\title{
Computational Exploration of Spectroscopic and Hydrogen Bonding Analysis of Direct Orange 26 Dye in Combination with Experimental and TD-DFT Calculations.
}

Mohamed A. Zayed ( $\square$ mazayed429@yahoo.com )

Chemistry Department, Faculty of Science, Cairo University https://orcid.org/0000-0003-2425-6329

Mahmoud A Noamaan

Cairo University Faculty of Science

Zahraa A.M Abo-Ayad

Cairo University Faculty of Science

\section{Research Article}

Keywords: DFT-TD-DFT, D0-26 dye, Normal modes /FTIR, NTOs, Bader's atoms-in-molecule (AIM), transfer length $(\Delta \mathrm{r})$-ground state $(\Delta \mu \mathrm{CT})$.

Posted Date: May 19th, 2021

DOl: https://doi.org/10.21203/rs.3.rs-502073/v1

License: (c) (1) This work is licensed under a Creative Commons Attribution 4.0 International License.

Read Full License 


\title{
Computational Exploration of Spectroscopic and hydrogen bonding analysis of Direct orange 26 Dye in combination with experimental and TD-DFT calculations.
}

\section{By}

\author{
Mohamed A. Zayed ${ }^{1 *}$, Mahmoud A. Noamaan², Zahraa A. M. Abo-Ayad ${ }^{1}$ \\ ${ }^{1}$ Chemistry Department, Faculty of Science, Cairo University, 12613 Giza, A.R. Egypt \\ ${ }^{2}$ Mathematics Department, Faculty of Science, Cairo University, 12613 Giza, A.R. Egypt
}

\begin{abstract}
:
The importance of this study stems from, it concentrates on new approach applying both practical and theoretical aspects to study structure of Direct orange dye 26 (DO-26) as an important dye widely used for dyeing of cotton or viscose for red orange direct printing. It also can be used for silk, wool, polyvinyl alcohol, polyamide fiber fabric and pulp dyeing. It proficiently compare practical with theoretical results of structural identification of the given important dye, via carful inspection of various phenomena detected in its two symmetrical arms around urea center. Direct orange dye 26 (DO-26) structure has been studied applying both practical spectroscopic and theoretical investigations. DFT-B3LYP/6-311++G(d,p) calculations are performed to investigate its structure, and the electronic vibrational properties. Correlation is found between experimental and calculated data. An intra-molecular hydrogen bonding interaction had been detected and characterized in dye skeleton using Atoms-in-molecule analysis employment. The hydrogen bonding present in the dye structure affecting its vibrational properties had been discussed. Natural population analysis like HOMO and LUMO and high quality molecular electrostatic potential plots along with various electronics had been presented at the same level of theory. Chemical reactivity descriptors from conceptual density functional theory point of view, structure activity relationship descriptor were obtained. The experimental UV/Visible and FT-IR spectral data of the dye DO-26 (D1) had been presented. These data had been supported by TD-DFT calculations to simulate the experimental spectra with computing the natural transition orbitals (NTO) and the orbital composition. The variation of charge transfer length $(\Delta \mathrm{r})$ and variation in its dipole moment with respect to ground state $\left(\Delta \mu_{\mathrm{CT}}\right)$ had been computed in order to study the charge redistribution due to the excitations. Actually there is a problem that, degradation of this dye in wastewater by different techniques leads to various unknown fragments but on using theoretical possibilities it can be expected what happened in practical work.
\end{abstract}

Keywords: DFT-TD-DFT, DO-26 dye; Normal modes /FTIR, NTOs, Bader's atoms-in-molecule (AIM), transfer length $(\Delta \mathrm{r})$-ground state $(\Delta \mu \mathrm{CT})$.

*Corresponding Author: e-mail: mazayed429@yahoo.com, Tel; 002-01005776675 


\section{Highlights}

$>$ This research deals with both practical and theoretical aspects to study structure of Direct orange dye 26 (DO-26).

$>$ It is an important dye widely used for dyeing of cotton, silk, wool, polyamide fiber and pulp dyeing.

$>$ The experimental UV/Visible and FT-IR spectral data of the dye DO-26 (D1) had been presented.

$>$ This study involved carful inspection of various phenomena detected in its two symmetrical arms around urea center.

$>$ DFT-B3LYP/6-311++G(d,p) calculations are performed to investigate its structure, and the electronic vibrational properties.

\section{Introduction}

The relatively large direct dyes molecules are of great high affinity to cellulose fibers and mostly bind to them via Vander Waal forces. Direct dyes are those of more than one azo group, phthalocyanine, stilbene or oxazine containing compounds. In the color index, considered the direct dyes form the second largest dye class with respect to the amount of different dyes [1]. DO-26 is reddish orange to light yellowish red color textile dye. Therefore; DO-26 can be used for dyeing cotton or viscose for red orange direct printing. It also can be used for silk, wool, polyvinyl alcohol, polyamide fiber fabric and pulp dyeing [2-5]. The commercial dyestuff DO-26 has a general formula $\mathrm{C}_{33} \mathrm{H}_{22} \mathrm{~N}_{6} \mathrm{Na}_{2} \mathrm{O}_{9} \mathrm{~S}_{2}$ of M.Wt. $=756.67 \mathrm{~g} \mathrm{~mol}^{-1}[6]$.

Pollution of water by dyes is a serious problem in developed countries. Approximately, $1-10 \%$ or more of dyes are discharged into waste streams without treatment by the textile industry worldwide. The effluents from the textile dyeing industry contain many organic pollutants and are a serious environmental hazard because of their lasting color, high chemical oxygen demand, and non-biodegradability [6]. Therefore, the understanding spectroscopic vibrational, electronic structural, tautomerism, electronic excitation, chemical reactivity and hydrogen bonding analysis of DO-26 to removal of dyes from waste water are a challenge for the affected industries.

DFT has been considered as an efficient tool for dying structural and vibrational properties of biomolecules $[7,8]$. DFT when incorporated by proper functional exchange-correlation; it provides sufficient confidence about the results. For computational low cost B3LYP hybrid functions became popular because of its accuracy; it is combined with Becke three parameters exchanges and 
with Lee, Yang and Parr's correlation. The B3LYP function combined with 6-311++G(d,p) basis set were used to calculate structure and vibrational properties of direct dye DO-26 molecule. On comparison of FTIR and UV-Visible spectra of DO-26 are shown good correlations between experimental and computational data. Most molecular calculated properties were electronic and thermodynamic. It also involved estimation of chemical reactivity and reaction paths. In DFT also Natural population analysis (NPA), HOMO, LUMO and molecular electrostatic potential (MESP) surfaces were calculated. They were used to discuss resulting intra-molecular charge transfers and electron density distribution.

Hydrogen bonding plays a pivotal role in determining the structures and properties of biomolecules [9]. The study of hydrogen bonding phenomena had been successfully studied applying Bader's atoms-in-molecule (AIM) theory [10]. The nature and strength of various types of hydrogen-bonded interactions had been efficiently described by the AIM theory. The AIM theory is able to describe the change in electron density distribution in a molecule as a result of either bond formation or complex formation. The reliability and stability in the values of AIM parameters have been studied and it was found that they are almost independent of basis set on the use of functional B3LYP in DFT [11]. However, it has been noticed that B3LYP function estimates weak intramolecular interactions as well as charge transfer effects [11-13].

\section{Experimental}

\subsection{Chemicals and procedures}

DO-26 was purchased from Anil Dyes and Chemicals Industries (India). A Perkin Elmer lambda 4B spectrophotometer had been used for measurements of the UV/Visible absorption spectra of the dye using $1.0 \mathrm{~cm}$ fused quartz cells at room temperature. A stock solution $(400 \mathrm{mg} / \mathrm{L})$ of Direct orange textile dye with the M.Wt. $=756.67 \mathrm{~g} \mathrm{~mol}^{-1}$ was prepared by dissolving $200 \mathrm{mg}$ in small amount of distilled water, then the solution was completed to $500 \mathrm{~mL}$ measuring flask. Dilute aqueous solutions of $\left(1.057 \times 10^{-3} \mathrm{M}\right)$ DO-26 were used for most measurements in $10 \mathrm{~mL}$ measuring flask.

The FT-IR spectra of $\mathrm{KBr}$ discs containing D1 had been measured at wavenumber region $4000-400 \mathrm{~cm}^{-1}$ using FTIR 4100, JASCO spectrophotometer.

\subsection{Computational details}

The Gaussian 09W software package [14] had been used for theoretical calculations. The molecular geometry for the studied compound had been fully optimized using density functional theory B3LYP method by using 6-311++G(d,p) basis set [15, 16]. Where (B3) [17-19] stands for Becke's three parameters combined with gradient-corrected functions of Lee, Yang and Parr (LYP) [20], During geometry optimization no symmetry constrains had been applied $[21,22]$. The choice of 
basis set 6-311++G(d, p) is mainly due to its flexibility, accuracy, consistent and better performance when using diffused Gaussian type triple- $\zeta$ potential [23, 24]. The vibrational frequencies have been determined and checked and proved that, all structures correspond to true minima of the potential energy surface at the same level of theory.

The Gaussian 09W software package has been used for NBO calculations using NBO 3.1 program implemented in the same program. The Gauss View version 5.0.9 [25] involving Chemcraft version 1.6 package [26] had been used throughout this work to optimize the structures of tested compounds. In addition, the Multiwfn v3.8 software program [27] has been used to compute quantum chemical descriptors from point of view of conceptual density functional theory (CDFT). The Multiwfn v3.8 software program [27] has been also used for Atom in molecule (AIM) analysis. The vertical linear-response TD-DFT approximation[28] has been also used for calculation of the first 80 low-lying excited states. The Polarizable Continuum Model (PCM) [29, 30] has been included in all steps of a modeling of bulk solvent effects.

Computing the natural transition orbitals (NTO) [31] have been used in analyzing the electronic properties of tested molecules excited states. The molecular fragments to occupy (occ.NTOs) and virtual natural transition orbitals (virt NTOs) had been performed by the orbital composition analysis taking into consideration the Hirshfld percent contributions. The Multi wave function v3.8 software program [27] had been used to estimate the electronic transitions between the ground state $\left(\mathrm{S}_{0}\right)$ and the low-lying singlet excited states $\left(\mathrm{S}_{\mathrm{n}}\right)$. In order to study the charge redistribution due to the excitations in tested molecules; the variation in dipole moment with respect to ground state $(\Delta \mu \mathrm{CT})[27]$ and the charge transfer length $(\Delta \mathrm{r})[32][33]$ were computed.

The VMD 1.9 program [33] has been used for rendering the color mapped isosurface graphs of electrostatic potential (ESP) of the ground states of the studied dye; based on the data outputted by Multiwfn program. The VibAnalysis code [34, 35] with corresponding to VEDA program [36] has been used for calculation of the potential energy distribution (PED) for various vibrational normal modes of the studied DO-26 dye (D1).

\section{Results and discussions}

\subsection{Density functional theory (DFT) studies}

The molecular electrostatic potential maps, bond lengths, bond angles and dihedral angles as the optimized geometrical parameters were calculated. Also natural charges, natural population analysis, reactivity descriptors, and energetic were computed. All of these calculated parameters were analyzed for the studied dye D1 both in water and gas phases of the ground state and compared with the practical elemental analyses and spectroscopic data. 


\subsubsection{Optimized structure and hydrogen bonding of D1}

Table (1) and Figure 1 present the computed parameters of D1 in this work; such as optimized geometry, numbering system, vector of the dipole moment, bond lengths, bond angles and dihedral angles.

Table 1. The values of computed parameters of DO-26 dye (D1) using B3lyp/6-311++G(d,p) (level of theory; selected bond lengths $\left(\mathrm{A}^{\mathrm{o}}\right)$, bond angles and dihedral angles).

\begin{tabular}{|c|c|c|c|c|c|}
\hline Coordinate & $\begin{array}{l}\text { Bond } \\
\text { length }\left(A^{0}\right)\end{array}$ & Coordinate & $\begin{array}{l}\text { Bond } \\
\text { Angles }\end{array}$ & Coordinate & $\begin{array}{l}\text { Dihedral } \\
\text { angles }\end{array}$ \\
\hline $\mathrm{R}(\mathrm{C} 1, \mathrm{O} 2)$ & 1.223 & $A(N 3, C 7, C 8)$ & 117.64 & $\mathrm{D}(\mathrm{O} 2, \mathrm{C} 1, \mathrm{~N} 4, \mathrm{C} 40)$ & 5.74 \\
\hline $\mathrm{R}(\mathrm{C} 1, \mathrm{~N} 3)$ & 1.393 & $\mathrm{~A}(\mathrm{~N} 3, \mathrm{C} 7, \mathrm{C} 16)$ & 122.81 & $\mathrm{D}(\mathrm{N} 3, \mathrm{C} 1, \mathrm{~N} 4, \mathrm{C} 40)$ & -175.86 \\
\hline $\mathrm{R}(\mathrm{C} 1, \mathrm{~N} 4)$ & 1.377 & $\mathrm{~A}(\mathrm{C} 8, \mathrm{C} 7, \mathrm{C} 16)$ & 119.44 & $\mathrm{D}(\mathrm{C} 1, \mathrm{~N} 3, \mathrm{C} 7, \mathrm{C} 8)$ & -151.94 \\
\hline $\mathrm{R}(\mathrm{N} 3, \mathrm{H} 6)$ & 1.010 & $\mathrm{~A}(\mathrm{C} 7, \mathrm{C} 8, \mathrm{C} 9)$ & 121.67 & $\mathrm{D}(\mathrm{C} 1, \mathrm{~N} 3, \mathrm{C} 7, \mathrm{C} 16)$ & 31.98 \\
\hline $\mathrm{R}(\mathrm{N} 3, \mathrm{C} 7)$ & 1.411 & $\mathrm{~A}(\mathrm{C} 12, \mathrm{C} 11, \mathrm{~S} 21)$ & 121.12 & $\mathrm{D}(\mathrm{C} 1, \mathrm{~N} 4, \mathrm{C} 40, \mathrm{C} 41)$ & -174.24 \\
\hline $\mathrm{R}(\mathrm{N} 4, \mathrm{H} 5)$ & 1.010 & $\mathrm{~A}(\mathrm{C} 11, \mathrm{C} 12, \mathrm{C} 13)$ & 120.19 & $\mathrm{D}(\mathrm{C} 1, \mathrm{~N} 4, \mathrm{C} 40, \mathrm{C} 49)$ & 6.93 \\
\hline $\mathrm{R}(\mathrm{N} 4, \mathrm{C} 40)$ & 1.411 & $\mathrm{~A}(\mathrm{C} 11, \mathrm{C} 12, \mathrm{~N} 26)$ & 116.82 & $\mathrm{D}(\mathrm{N} 3, \mathrm{C} 7, \mathrm{C} 8, \mathrm{C} 9)$ & -175.75 \\
\hline $\mathrm{R}(\mathrm{C} 11, \mathrm{C} 12)$ & 1.454 & $\mathrm{~A}(\mathrm{C} 13, \mathrm{C} 12, \mathrm{~N} 26)$ & 122.99 & $\mathrm{D}(\mathrm{C} 8, \mathrm{C} 9, \mathrm{C} 10, \mathrm{C} 11)$ & -179.19 \\
\hline $\mathrm{R}(\mathrm{C} 11, \mathrm{~S} 21)$ & 1.851 & $\mathrm{~A}(\mathrm{C} 12, \mathrm{C} 13, \mathrm{C} 14)$ & 117.12 & $\mathrm{D}(\mathrm{C} 8, \mathrm{C} 9, \mathrm{C} 14, \mathrm{C} 13)$ & -179.99 \\
\hline $\mathrm{R}(\mathrm{C} 12, \mathrm{C} 13)$ & 1.475 & $\mathrm{~A}(\mathrm{C} 12, \mathrm{C} 13, \mathrm{O} 25)$ & 121.45 & $\mathrm{D}(\mathrm{C} 9, \mathrm{C} 10, \mathrm{C} 11, \mathrm{~S} 21)$ & 178.10 \\
\hline $\mathrm{R}(\mathrm{C} 12, \mathrm{~N} 26)$ & 1.321 & $\mathrm{~A}(\mathrm{~N} 26, \mathrm{~N} 27, \mathrm{C} 28)$ & 119.70 & $\mathrm{D}(\mathrm{C} 11, \mathrm{C} 12, \mathrm{C} 13, \mathrm{O} 25)$ & 179.93 \\
\hline $\mathrm{R}(\mathrm{C} 13, \mathrm{O} 25)$ & 1.252 & $\mathrm{~A}(\mathrm{~N} 26, \mathrm{~N} 27, \mathrm{H} 39)$ & 117.77 & $\mathrm{D}(\mathrm{N} 26, \mathrm{C} 12, \mathrm{C} 13, \mathrm{C} 14)$ & -179.42 \\
\hline $\mathrm{R}(\mathrm{N} 26, \mathrm{~N} 27)$ & 1.303 & $\mathrm{~A}(\mathrm{C} 28, \mathrm{~N} 27, \mathrm{H} 39)$ & 122.53 & $\mathrm{D}(\mathrm{N} 26, \mathrm{C} 12, \mathrm{C} 13, \mathrm{O} 25)$ & 0.15 \\
\hline $\mathrm{R}(\mathrm{N} 27, \mathrm{C} 28)$ & 1.401 & $\mathrm{~A}(\mathrm{~N} 27, \mathrm{C} 28, \mathrm{C} 29)$ & 121.09 & $\mathrm{D}(\mathrm{C} 11, \mathrm{C} 12, \mathrm{~N} 26, \mathrm{~N} 27)$ & 179.90 \\
\hline $\mathrm{R}(\mathrm{N} 27, \mathrm{H} 39)$ & 1.030 & $\mathrm{~A}(\mathrm{~N} 4, \mathrm{C} 40, \mathrm{C} 41)$ & 117.23 & $\mathrm{D}(\mathrm{C} 13, \mathrm{C} 12, \mathrm{~N} 26, \mathrm{~N} 27)$ & -0.32 \\
\hline $\mathrm{R}(\mathrm{C} 44, \mathrm{C} 45)$ & 1.455 & $\mathrm{~A}(\mathrm{~N} 4, \mathrm{C} 40, \mathrm{C} 49)$ & 123.01 & $\mathrm{D}(\mathrm{C} 12, \mathrm{~N} 26, \mathrm{~N} 27, \mathrm{C} 28)$ & 179.75 \\
\hline $\mathrm{R}(\mathrm{C} 44, \mathrm{~S} 54)$ & 1.850 & $\mathrm{~A}(\mathrm{C} 41, \mathrm{C} 40, \mathrm{C} 49)$ & 119.75 & $\mathrm{D}(\mathrm{C} 12, \mathrm{~N} 26, \mathrm{~N} 27, \mathrm{H} 39)$ & -0.15 \\
\hline $\mathrm{R}(\mathrm{C} 45, \mathrm{C} 46)$ & 1.476 & $\mathrm{~A}(\mathrm{C} 45, \mathrm{C} 44, \mathrm{~S} 54)$ & 120.81 & $\mathrm{D}(\mathrm{N} 26, \mathrm{~N} 27, \mathrm{C} 28, \mathrm{C} 29)$ & -0.30 \\
\hline $\mathrm{R}(\mathrm{C} 45, \mathrm{~N} 59)$ & 1.319 & $\mathrm{~A}(\mathrm{C} 44, \mathrm{C} 45, \mathrm{C} 46)$ & 120.12 & $\mathrm{D}(\mathrm{N} 26, \mathrm{~N} 27, \mathrm{C} 28, \mathrm{C} 33)$ & 179.76 \\
\hline $\mathrm{R}(\mathrm{C} 46, \mathrm{O} 58)$ & 1.253 & $\mathrm{~A}(\mathrm{C} 44, \mathrm{C} 45, \mathrm{~N} 59)$ & 116.82 & $\mathrm{D}(\mathrm{N} 4, \mathrm{C} 40, \mathrm{C} 41, \mathrm{C} 42)$ & -178.74 \\
\hline $\mathrm{R}(\mathrm{N} 59, \mathrm{~N} 60)$ & 1.306 & $\mathrm{~A}(\mathrm{C} 46, \mathrm{C} 45, \mathrm{~N} 59)$ & 123.06 & $\mathrm{D}(\mathrm{C} 40, \mathrm{C} 41, \mathrm{C} 42, \mathrm{C} 43)$ & 179.90 \\
\hline $\mathrm{R}(\mathrm{N} 60, \mathrm{C} 61)$ & 1.400 & $\mathrm{~A}(\mathrm{C} 45, \mathrm{C} 46, \mathrm{C} 47)$ & 117.16 & $\mathrm{D}(\mathrm{C} 40, \mathrm{C} 41, \mathrm{C} 42, \mathrm{C} 47)$ & -0.06 \\
\hline $\mathrm{R}(\mathrm{N} 60, \mathrm{H} 72)$ & 1.030 & $\mathrm{~A}(\mathrm{C} 45, \mathrm{C} 46, \mathrm{O} 58)$ & 121.27 & $\mathrm{D}(\mathrm{C} 41, \mathrm{C} 42, \mathrm{C} 47, \mathrm{C} 46)$ & -179.92 \\
\hline $\mathrm{A}(\mathrm{O} 2, \mathrm{C} 1, \mathrm{~N} 3)$ & 119.22 & $\mathrm{~A}(\mathrm{C} 47, \mathrm{C} 46, \mathrm{O} 58)$ & 121.58 & $\mathrm{D}(\mathrm{N} 59, \mathrm{C} 45, \mathrm{C} 46, \mathrm{O} 58)$ & -0.28 \\
\hline $\mathrm{A}(\mathrm{O} 2, \mathrm{C} 1, \mathrm{~N} 4)$ & 124.90 & $\mathrm{~A}(\mathrm{~N} 59, \mathrm{~N} 60, \mathrm{C} 61)$ & 119.48 & $\mathrm{D}(\mathrm{C} 44, \mathrm{C} 45, \mathrm{~N} 59, \mathrm{~N} 60)$ & 179.90 \\
\hline $\mathrm{A}(\mathrm{N} 3, \mathrm{C} 1, \mathrm{~N} 4)$ & 115.86 & $\mathrm{~A}(\mathrm{~N} 59, \mathrm{~N} 60, \mathrm{H} 72)$ & 117.72 & $\mathrm{D}(\mathrm{C} 45, \mathrm{~N} 59, \mathrm{~N} 60, \mathrm{C} 61)$ & -179.67 \\
\hline $\mathrm{A}(\mathrm{C} 1, \mathrm{~N} 3, \mathrm{H} 6)$ & 110.27 & $\mathrm{~A}(\mathrm{C} 61, \mathrm{~N} 60, \mathrm{H} 72)$ & 122.80 & $\mathrm{D}(\mathrm{C} 45, \mathrm{~N} 59, \mathrm{~N} 60, \mathrm{H} 72)$ & 0.06 \\
\hline $\mathrm{A}(\mathrm{C} 1, \mathrm{~N} 3, \mathrm{C} 7)$ & 133.77 & $\mathrm{~A}(\mathrm{~N} 60, \mathrm{C} 61, \mathrm{C} 62)$ & 121.01 & $\mathrm{D}(\mathrm{N} 59, \mathrm{~N} 60, \mathrm{C} 61, \mathrm{C} 62)$ & 0.18 \\
\hline $\mathrm{A}(\mathrm{H} 6, \mathrm{~N} 3, \mathrm{C} 7)$ & 115.93 & $\mathrm{D}(\mathrm{O} 2, \mathrm{C} 1, \mathrm{~N} 3, \mathrm{H} 6)$ & 11.81 & D(N60,C61,C62,C63) & 179.97 \\
\hline $\mathrm{A}(\mathrm{C} 1, \mathrm{~N} 4, \mathrm{H} 5)$ & 116.56 & $\mathrm{D}(\mathrm{O} 2, \mathrm{C} 1, \mathrm{~N} 3, \mathrm{C} 7)$ & -170.64 & $\mathrm{D}(\mathrm{C} 41, \mathrm{C} 42, \mathrm{C} 47, \mathrm{C} 48)$ & 0.00 \\
\hline $\mathrm{A}(\mathrm{C} 1, \mathrm{~N} 4, \mathrm{C} 40)$ & 128.15 & $\mathrm{D}(\mathrm{N} 4, \mathrm{C} 1, \mathrm{~N} 3, \mathrm{H} 6)$ & -166.69 & $\mathrm{D}(\mathrm{C} 44, \mathrm{C} 45, \mathrm{C} 46, \mathrm{O} 58)$ & 179.89 \\
\hline $\mathrm{A}(\mathrm{H} 5, \mathrm{~N} 4, \mathrm{C} 40)$ & 115.18 & $\mathrm{D}(\mathrm{N} 4, \mathrm{C} 1, \mathrm{~N} 3, \mathrm{C} 7)$ & 10.86 & $\mathrm{D}(\mathrm{N} 59, \mathrm{C} 45, \mathrm{C} 46, \mathrm{C} 47)$ & 179.67 \\
\hline
\end{tabular}

Values are mean $\pm S D$ triplicate assays. 


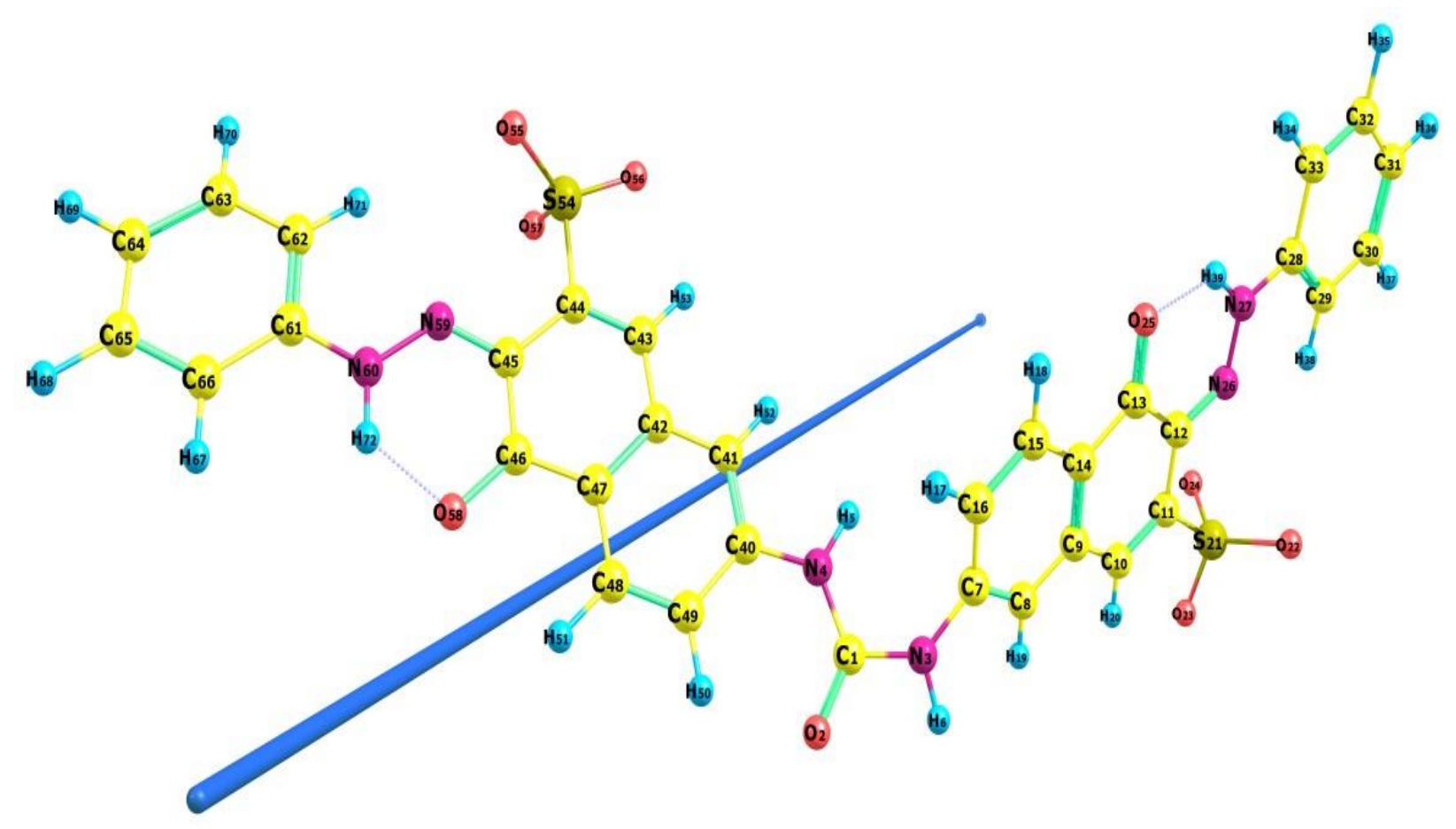

DO-26 dye (D1)

Figure 1.The optimized geometry of DO-26 dye (D1) compounds using B3LYP/6-311++G(d,p) level of theory, the numbering system and vector of dipole moment.

The data in Table 1 refer to the maximum $\mathrm{C}-\mathrm{C}$ bond length (among others) of $1.454 \AA$ in naphthalene ring system that in good agreement with the reported value of $1.42 \AA[37,38]$. The bond angle C37-C36-C27 calculated is found to be $119.75 \mathrm{~A}^{\mathrm{o}}$; it shows excellent agreement with the reported value of $119.4 \AA[37,38]$. The dye D1 is considered urea derivative fragment in which the urea calculated bonds $\mathrm{C} 1-\mathrm{O} 2, \mathrm{C} 1-\mathrm{N} 3$ and $\mathrm{C} 1-\mathrm{N} 4$ give values of $1.223,1.393$ and $1.377 \AA$. The corresponding practical values of these bonds in D1 are found to be $1.245,1.345$ and $1.329 \AA$. The selected angles in the tested dye O2C1N3 and $\mathrm{N} 3 \mathrm{C} 1 \mathrm{~N} 4$ are found to be of the values $119.22^{\circ}$ and $115.86^{\circ}$; while the respective angles in urea are found to be $120.34^{\circ}$ and $118.29^{\circ}[37,38]$. Thus, bonds are affected by the presence of two arms of D1 (Figure 1) with sequence (right arm: C7 to H39) and (left arm: C40 to H58).

The computed values of dihedral angles around central urea derivatives are represented in Table 1. They show that, the angle N4C1N3C7 is of $10.9^{\circ}$ degree right arm out of plane and the angle $\mathrm{O} 2 \mathrm{C} 1 \mathrm{~N} 4 \mathrm{C} 40$ is of $5.74^{\circ}$ and degree left arm out of plane. This indicates that the carbon derivative is almost in the same molecular plane of urea. Also, atoms in angles C8C9C10C11, C11C12C13O25, C11C12N26N27, N26N27C28C29, $\mathrm{N} 26 \mathrm{~N} 27 \mathrm{C} 28 \mathrm{C} 33$ of the values $180,180,179.9,-0.3,179.76$ degree; refer to the planarity of 
right arm component due to symmetry of the molecular structure. The left arm one is almost planar; which represented by angles N60C61C62C63, C41C42C47C48, C44C45C46O58 of values 180, 0.0 and 180.0 degrees respectively.

AIM theory calculations refer to the presence of hydrogen bonds in the skeleton of D1; that follows Koch and Popelier criterion [39]. The hydrogen bonding requires the existence of bond critical point (BCP) for the 'proton donor $(\mathrm{H})$ and acceptor (A)' contact. Applying this theory to DO-26 it shows a lot of intra-molecular hydrogen bonding interaction $\mathrm{O} 25-\mathrm{H} 39$, O58-H72, O2-H50, O23H20, O74-H53 in diazo-carbonyl fragment in two arms. The application of this theory [39] actually required the value of electron density (q) in the range 0.002-0.040 a.u. and corresponding Laplacian $\left(\nabla^{2} \rho\right)$ should be $0.024-0.139$ a.u. These parameters have been calculated for the studied D1 at BCP with sequence $\mathrm{O} 25 \ldots \mathrm{H} 39, \mathrm{O} 58 \ldots \mathrm{H} 72, \mathrm{O} 2 \ldots \mathrm{H} 50, \mathrm{O} 23 \ldots \mathrm{H} 20, \mathrm{O} 74 \ldots \mathrm{H} 53$ along with geometrical parameters of H-bonds and the data obtained are listed in Table 2.

Table 2. The calculated selected geometrical parameters (a.u) using B3lyp/6-311++G (d,p) level of theory, bond length $(\AA)$ and binding energy (kcal/mol) of DO-26 dye (D1).

There are three types of H-bonds have been detected in the basis of D1 topology [40] via calculated parameters. The characterization has been followed Rozas et al. [40] demands; at BCP in which; $\nabla^{2} \rho$ and $H<0$ for strong $\mathrm{H}$-bonding of covalent character. It also should be $\nabla^{2} \rho>0$ And $\mathrm{H}<0$ for medium $\mathrm{H}$-bond of partially covalent nature. Alternatively it should be $\nabla^{2} \rho>0$ and $\mathrm{H}>0$ for weak H-bond. From the presented data in Table 2 it is clear that; Laplacian of charge density is positive for all BCP, $\nabla^{2} \rho=0.15,0.15$, 0.066, 0.061, 0.062 and 0.047. Also the energy density $\mathrm{H}<0$ for the first two $\mathrm{N} 27 \mathrm{H} 39 \ldots \mathrm{O} 25$ and $\mathrm{N} 60 \mathrm{H} 72 \ldots \mathrm{O} 58$ and others is $\mathrm{H}>0$ suggesting the interaction to be medium $\mathrm{H}$-bond of partially covalent nature in $\mathrm{N} 27 \mathrm{H} 39 \ldots \mathrm{O} 25$ and $\mathrm{N} 60 \mathrm{H} 72 \ldots \mathrm{O} 58$ and weak in nature for all other BCP. The value of $\nabla^{2} \rho$ is found to be negative and small in magnitude for strong covalent interactions, as in [Mn(III) porphyrin]Cl-trimethoprim complex ( $\nabla^{2} \rho=-0.0786$ a.u.) [41]; and as in bis-dithiazolyl dimers [42]. By using $\mathrm{E}_{\text {int }}=(\mathrm{V})$ at $\mathrm{BCP}$ as proposed by Espinosa et al [43]; the energy of interactions occur in tested dye has been theoretically calculated. The estimated interaction energy values of hydrogen bonding in the given dye for bonds $\mathrm{O} 25 \ldots \mathrm{H} 39, \mathrm{O} 58 \ldots \mathrm{H} 72, \mathrm{O} 2 \ldots \mathrm{H} 50, \mathrm{O} 23 \ldots \mathrm{H} 20, \mathrm{O} 74 \ldots \mathrm{H} 53$ are found to be $-12.36,-12.41,-3.8,-3.53$ and $-3.57 \mathrm{kcal} / \mathrm{mol}$, respectively. These data indicate the medium $\mathrm{H}$-bond interactions for $\mathrm{N} 27 \mathrm{H} 39 . . \mathrm{O} 25$ and $\mathrm{N} 60 \mathrm{H} 72 \ldots \mathrm{O} 58$ bonds and other 
bond are of week interaction [44]. The binding energy more accurate values have been obtained by applying another prediction equation [45] and the found values for bonds $\mathrm{O} 25 \ldots \mathrm{H} 39, \mathrm{O} 58 \ldots \mathrm{H} 72, \mathrm{O} 2 \ldots \mathrm{H} 50, \mathrm{O} 23 \ldots \mathrm{H} 20, \mathrm{O} 74 \ldots \mathrm{H} 53$ are found to be $-8.78,-8.8$, $3.26,-2.73$ and $-2.8 \mathrm{kcal} / \mathrm{mol}$ respectively.

\subsubsection{The tautomeric relative stability of $D 1$}

From the above calculations and practical work data; the depicted three different tautomeric forms of the DO-26 (D1) dye are di-keto form (A, $\left.\mathrm{C}_{13}=\mathrm{O}_{25}, \mathrm{C}_{46}=\mathrm{O} 58\right)$, keto-enol forms (B and C) and di-enol forms (D and E) and corresponding four transition states (TS) (F-I) are suggested. The proposed relative potential energy surface diagram for different three tautomeric forms and TS of D1 (A-I), are represented in Figure 2.

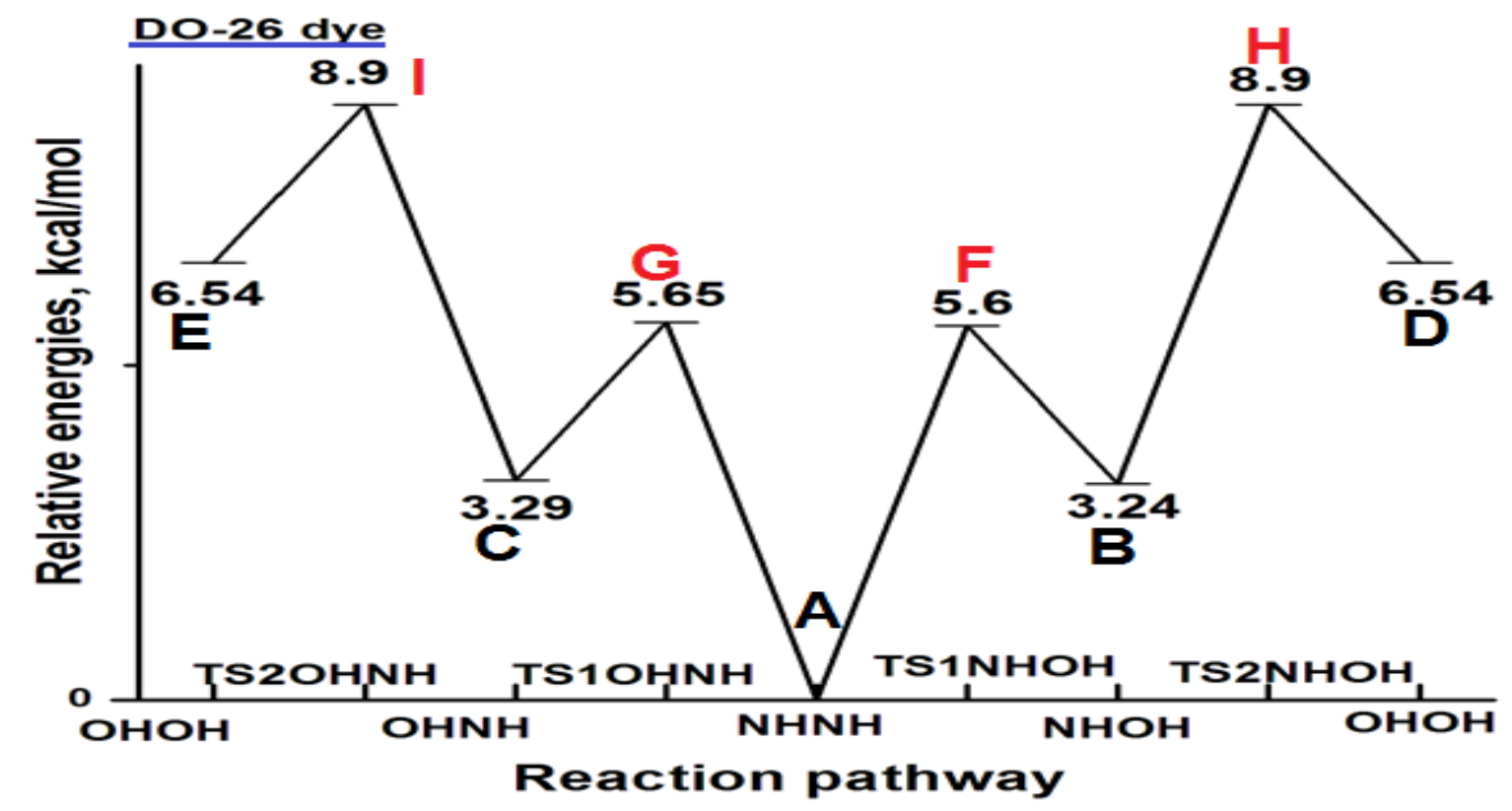

Fig. 2. Using the B3LYP/ 6-311++G(d,p) of the DFT theory; the calculated surface relative potential energy values are given for the different tautomeric forms transformations of DO-26 dye (D1).

Figure 2 represents data in this research; which give great benefit in explaining structural behavior of the studied dye and its stability. The DFT calculations reveal that the stability order of different forms (A-E) of the DO-26 dye is $\mathrm{A}>\mathrm{B}>\mathrm{C}>\mathrm{D}=\mathrm{E}$ as given by their calculated relative energy values of $0.0,3.24,3.29,6.54 \mathrm{Kcal} / \mathrm{mol}$ respectively. These data refer to the di-keto form of D1 is the most stable tautomer in the gas phase. This conclusion is confirmed by the calculated energy values of corresponding four transition states (TS) (F-I) with respect to A with 5.6, 5.65, 8.9 $\mathrm{Kcal} / \mathrm{mol}$ respectively; which have stability order of $\mathrm{F}<\mathrm{G}<\mathrm{H}=\mathrm{I}$ (see Figure 2). The stability of the di-keto form (A) relative to the keto-enol (B), enol-keto (C) and the di-enol (D) forms may be attributed to the increasing in the strain effects within the moiety of these forms. On inspection of supplementary material (Figure S1), one can find transfer of the single proton between the oxygen 
atoms (O25 or $\mathrm{O58})$. On the other hand proton is moved in opposite directions relative to the nitrogen atoms ( $\mathrm{N}_{27}$ or $\mathrm{N}_{60}$ ) (forms $\mathrm{B}$ and $\mathrm{C}$ ). It is also noticed that; form $\mathrm{C}$ is less stable than form $\mathrm{B}$; which may be attributed to the electrostatic attraction between the proton and the oxygen atom. The stability of $\mathbf{A}$ (the di-keto form) may be attributed to the planarity of right and left part arms for central carbonyl group $\mathrm{C} 1=\mathrm{O} 2$.

\subsubsection{Normal mode analysis and FT-IR of D1}

The vibrational normal mode analysis confirm that; the most of the calculated frequencies of the optimized geometry of D1 (Figure 1) are found to be real. Consequently; the D1 optimized geometry corresponds to a true minimum energy in the PES. The obtained frequency values applying the present theoretical model are scaled with a factor of 0.96 [46][46] to avoid errors due to neglect of inharmonic terms. All the vibrational modes are properly assigned applying the basis of PED. By using free VibAnalysis code [34, 35] with corresponding to VEDA program [36]; the various vibrational normal modes have been calculated. The calculated FTIR frequency intensities and assignments listed in Table 3; are selected in normal modes up to $400 \mathrm{~cm}^{-1}$. All normal modes with all details up to $400 \mathrm{~cm}^{-1}$ are presented in Table $\mathrm{S} 1$ as supplementary information.

Table 3. Selected vibrational normal modes of analysis, including FT-IR values, for D1 obtained using B3LYP/6-311+G (d,p) level of theory

Figure $(3 \mathrm{a}, \mathrm{b})$ presents simulated FT-IR spectra at 400 to $4000 \mathrm{~cm}^{-1}$ for DO-26 in comparison with experimental results. The DO-25 (D1) has two similar arms for the urea derivatives. Each arm is substituted naphthalene and benzene ring linked by diazonium fragment $(=\mathrm{N}-\mathrm{NH}-)$. The $\mathrm{N}-\mathrm{H}$ stretching frequencies of the rings are calculated and found to be in the range $3,473-3,133 \mathrm{~cm}^{-1}$; which is in good agreement with the found values in literature [47] of 3,200 and 3,500 $\mathrm{cm}^{-1}$ with strong or medium intensities. 


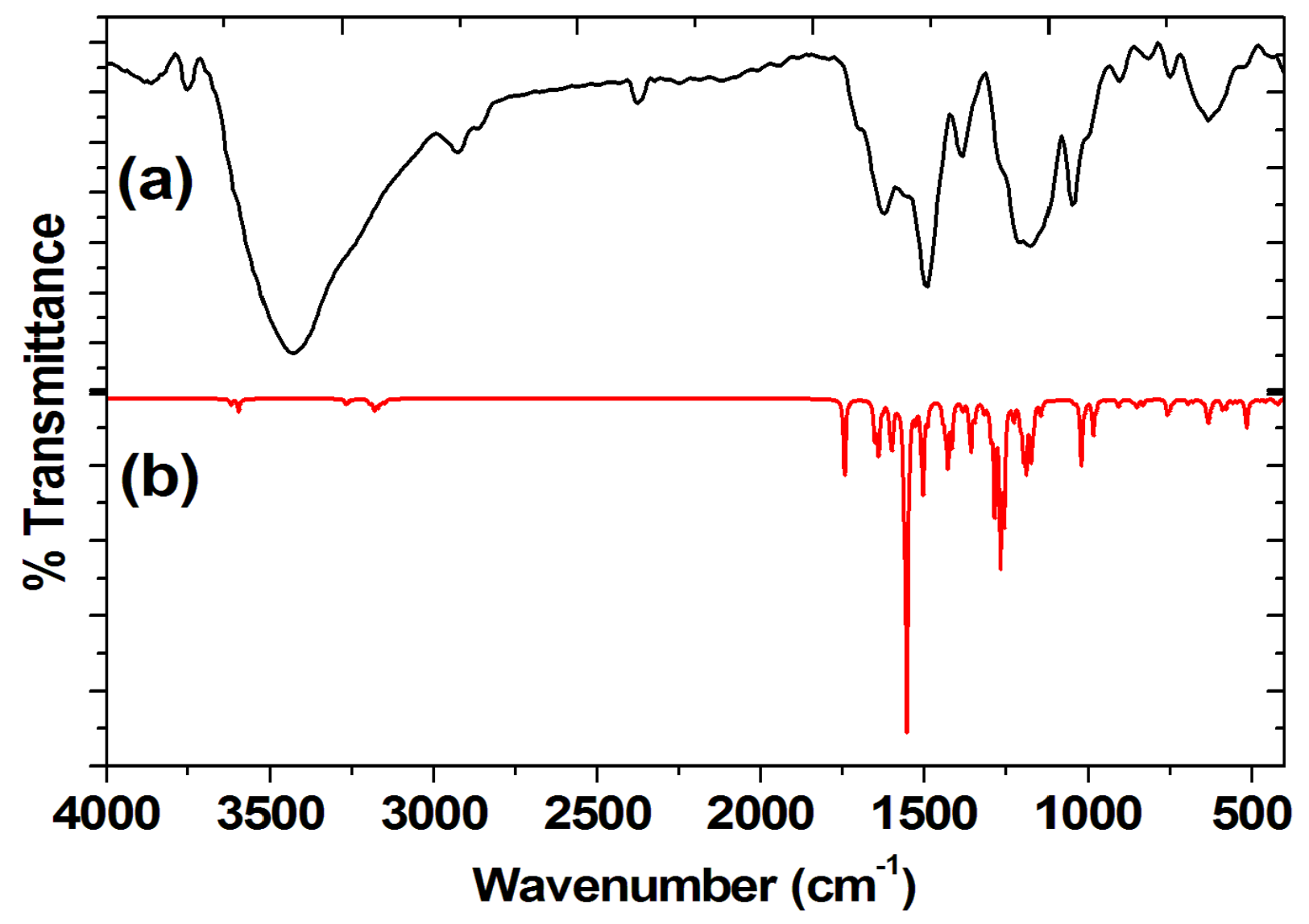

Figure 3. FT-IR spectra of the DO-26 dye (D1) in the region $400-4000 \mathrm{~cm}^{-1}$ : (a) Experimental spectra (b) simulated spectra.

$\mathrm{N}-\mathrm{H}$ stretching vibration with a PED of almost $90-100 \%$ is calculated at $3,473,3,450,3,138$ $3,133 \mathrm{~cm}^{-1}$ and presented in Table 3 . The FT-IR practical value corresponding to this band is found to be $3,466 \mathrm{~cm}^{-1}$. However, the $\mathrm{NH}$ group in acetyl-hydrazine molecule $\left(\mathrm{CH}_{3}-\mathrm{CO}-\mathrm{NH}-\mathrm{NH}_{2}\right)$, is detected at $3,445 \mathrm{~cm}^{-1}$ and confirmed by the calculated one found at $3,640 \mathrm{~cm}^{-1}$ by DFT [48]. The $\mathrm{N}-\mathrm{H}$ stretching band is apparently shifted due to hydrogen bonding with oxygen $\mathrm{O} 25$ or O58 attached to naphthalene ring. The inter-molecular hydrogen bonding in D1 is stronger than intramolecular H-bonding as indicated by difference in calculated and experimental frequencies of the same dye indicates that.

The rings $\mathrm{C}-\mathrm{H}$ stretching frequencies at the wavenumber range $3,117-3,024 \mathrm{~cm}^{-1}$ have been calculated. The $\mathrm{C}-\mathrm{H}$ stretching of $\mathrm{C} 49 \mathrm{H} 50$ group near to the $\mathrm{C}=\mathrm{O}$ of central urea has been detected at $3,086 \mathrm{~cm}^{-1}$; which were found to be at 3,000 and $3,100 \mathrm{~cm}^{-1}$ with medium intensities in the published work [47]. The calculated $\mathrm{C}=\mathrm{C}$ stretching vibrations and its mixing with other modes of naphthalene rings are found in lower region at frequency values of 1,574 and $1,559 \mathrm{~cm}^{-1}$ respectively. These theoretically calculated values are also correlated with that reported in literature [47] in which strong absorption band of naphthalene right arm has been detected at $1,571 \mathrm{~cm}^{-1}$ and falling range of $1,600-1,500 \mathrm{~cm}^{-1}$. 
The $\mathrm{C}-\mathrm{H}$ bending of ring systems frequencies in plane and out of plane are calculated and found to be ascertained with $\mathrm{C}-\mathrm{C}$ stretching region. The calculated $\mathrm{C}-\mathrm{H}$ vibrational mode of strong intensity for naphthalene ring is found to be at $1,120 \mathrm{~cm}^{-1}$. The naphthalene ring torsion modes are always found in even lower frequency region [47].

The $\mathrm{CH}_{2}$ stretching vibrations of weak intensities in the dye skeleton are detected at 2,954 and $2,907 \mathrm{~cm}^{-1}$. The $\mathrm{CH}_{2}$ bending vibration has been detected at $1,464 \mathrm{~cm}^{-1}$. The $\mathrm{C}-\mathrm{H}$ lying between N14 and R3 stretching vibration has been practically detected as strong intensity band at 2,904 $\mathrm{cm}^{-}$ 1. The calculated $\mathrm{C}=\mathrm{O}$ stretching band has been theoretically calculated at $1,625 \mathrm{~cm}^{-1}$; which actually fit the practically detected in FTIR value of D1 at $1,638 \mathrm{~cm}^{-1}$. These data are found to be in good correlation with the $\mathrm{C}=\mathrm{O}$ stretching as a very strong band in the region $1,680-1,640 \mathrm{~cm}^{-1}$ previously reported elsewhere [47]. The $\mathrm{C}-\mathrm{N}$ and $\mathrm{C}=\mathrm{N}$ stretching vibrations coupled with $\mathrm{N}-\mathrm{H}$ scissoring and $\mathrm{CCN}$ and $\mathrm{HNN}$ twisting vibrations respectively in acetyl-hydrazine molecule $\left(\mathrm{CH}_{3}-\right.$ $\mathrm{CO}-\mathrm{NH}-\mathrm{NH}_{2}$ ) are calculated and found to be 1,499 and $1,428 \mathrm{~cm}^{-1}$. These theoretically calculated values are actually correlated with the practically detected values in the wavenumber range at $1,460-1,430 \mathrm{~cm}^{-1}$ in the FT-IR of tested dye. All of these bands of acetyl-hydrazine molecule $\left(\mathrm{CH}_{3}-\mathrm{CO}-\mathrm{NH}-\mathrm{NH}_{2}\right)$ are found to be weak instead of intense band as previously reported [47]. The calculated frequencies belongs to $\mathrm{N}-\mathrm{N}$ stretching has been practically detected at 1,300 and 1,250 $\mathrm{cm}^{-1}$ respectively and bending vibrational deformation modes of the fragment of the same group has been practically detected at 1,352 and $680 \mathrm{~cm}^{-1}$. The theoretically calculated and experimental FTIR frequencies of D1 at $400-4000 \mathrm{~cm}^{-1}$ are listed in Table 3 and graphically represented in Figure 4.

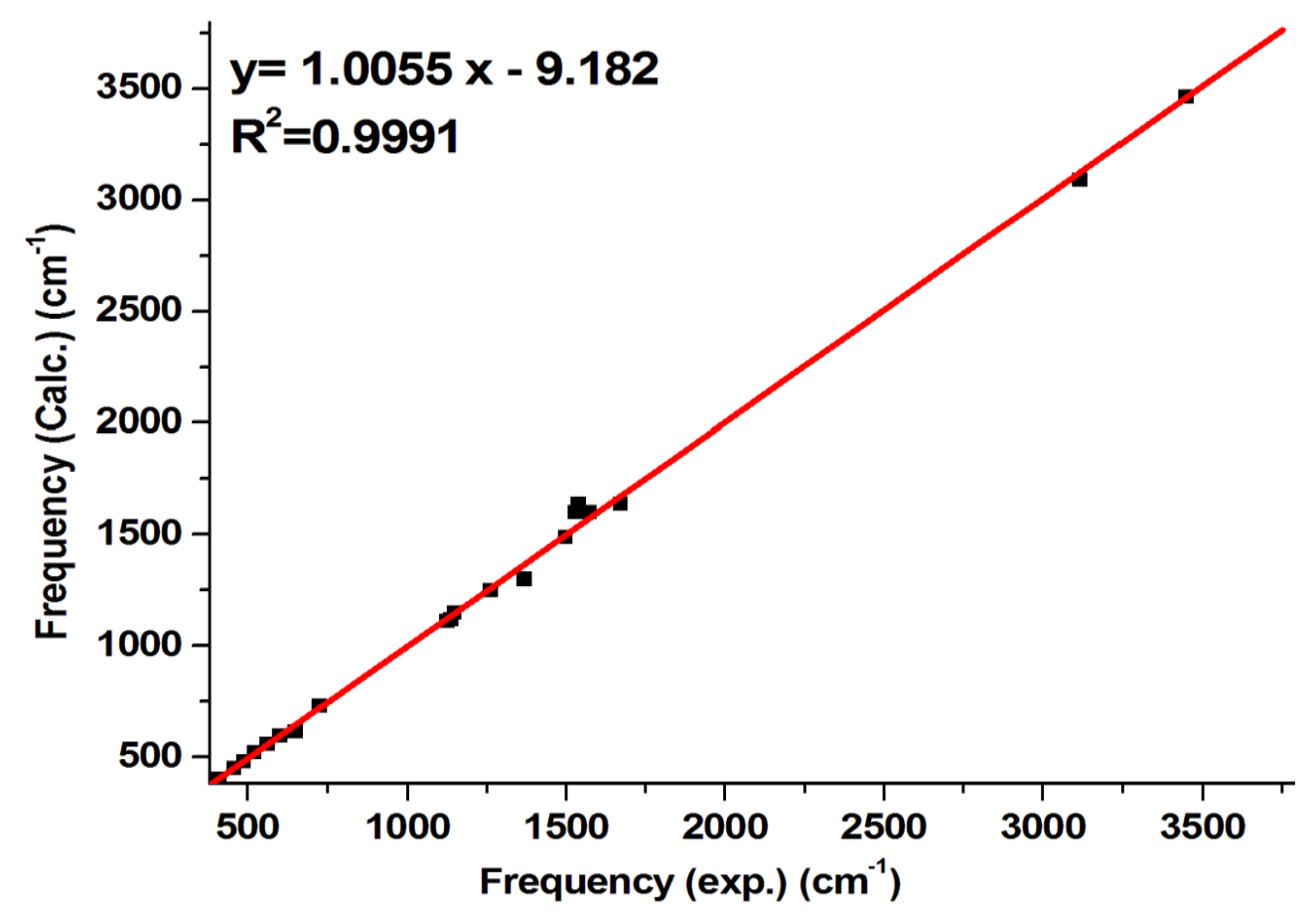

Figure 4. Correlation between experimental FT-IR and simulated IR spectra in the region 4000-400 $\mathrm{cm}^{-1}$ of the DO-26 dye (D1). 
Figure 4 shows a correlation between theoretically calculated and the practically detected frequencies in FT-IR of the dye DO-26. These data show good and correlation exists with a coefficient of 0.9991 . Such a correlation proved that the DFT/B3LYP scheme of theoretical calculation in the field of spectroscopy is efficiently reproduces the experimental results and can be used for vibrational analysis of biomolecules with a sufficient confidence.

\subsubsection{Natural charges and natural population analysis (NPA) of D1}

The NPA scheme at B3LYP/6-311++G(d, p) level had been used in theoretical calculation of atomic charges of the investigated molecule (D1) in gas. These charges are ranged from -1.001 to 2.299 e and the data obtained are depicted in Table 4. The obtained results proved that; this scheme is more reliable due to its low basis set dependency.

Table 4. Natural charge of selected atoms of DO-26 dye1 (D1) at B3lyp/6-311++G(d,p) level of theory.

Table 4 shows that; the carbon atoms in the skeleton of the dye DO-26 are either carrying positive or negative charges; it depends on its position. The negative charges are concentrated on $\mathrm{O} 23, \mathrm{O} 24, \mathrm{O} 25, \mathrm{O} 55, \mathrm{O} 56$ and $\mathrm{O} 57$ oxygen atoms of $\mathrm{SO}_{3}$ groups. It also has been seen that the charge is around -1.0 e on each atom. The maximum positive charges on sulpher atoms (S21 and $\mathrm{S} 54$ atoms of $\mathrm{SO}_{3}$ groups) have been detected. The nitrogen and oxygen atoms of urea and diazonium fragments are negatively charged and consequently they accept electrons. It is also noticed that; the increase of charge on N27 and N27 as compared to N26 and N59. The decrease in charge on $\mathrm{O} 25$ and $\mathrm{O} 58$ may be due to electron density transfer from proton donors N27H39 and $\mathrm{N} 60 \mathrm{H} 72$ to proton acceptors $\mathrm{O} 25$ and O58 involved in hydrogen bonding. It is finally noticed that; charges on hydrogen atoms have positive values.

\subsubsection{FMOs analysis}

Table 5 represents Frontier molecular orbitals (FMOs) data. The represented calculated quantum chemical parameters values are $\mathrm{E}_{\text {номо, }} \mathrm{E}_{\mathrm{Lumo}}$, energy gap ( $\left.\Delta \mathrm{E}_{\mathrm{gap}}\right)$, ionization energy (I), electron affinity (A) and Dipole moment [49-51].

Table 5. Energetic parameters and reactivity indices of synthesized DO-26 dye1 (D1) using B3lyp/6-311++G(d,p) level of theory.

\begin{tabular}{|c|c|c|c|c|c|c|c|}
\hline \multirow{2}{*}{$\begin{array}{l}\text { Frontier molecular } \\
\text { orbitals (FMOs) }\end{array}$} & ET,au & EHOMO,au & ELUMO,au & Eg,eV & $\mathrm{I}, \mathrm{eV}$ & A,eV & $\mu, \mathrm{D}$ \\
\hline & -3073.35409 & -0.06336 & 0.02557 & 2.42 & 1.72 & -0.70 & 10.98 \\
\hline \multirow{2}{*}{$\begin{array}{l}\text { Global Reactivity } \\
\text { Descriptor (GRD) }\end{array}$} & $\mathrm{X}, \mathrm{eV}$ & $\eta, e V$ & S,eV & V,eV & $\omega, \mathrm{eV}$ & $\mathrm{N}, \mathrm{eV}$ & \\
\hline & 0.51 & 1.21 & 0.41 & -0.51 & 0.11 & 2.49 & \\
\hline
\end{tabular}

Values are mean $\pm S D$ triplicate assays

The HOMO (ionization potential I= - EHOMO) energy value usually determines the donating power of electrons of the tested group. Its high value indicates the ease of donating electron to the unoccupied orbital of the receptor molecule. The small value of ELumo (electron 
affinities $\mathrm{A}=-$ ELUMO).means more able to accept electron. The calculated Eномо of the tested dye is found to be $-1.724 \mathrm{eV}$; which is located on the $\mathrm{SO}_{3}$ group system of right arm. On the other hand the Elumo, of DO-26 is found to be $0.696 \mathrm{eV}$; which is mainly contributed by all left arm of the dye molecule. The energy ( $\Delta \mathrm{E}_{\mathrm{gap}}$ ) between HOMO and LUMO usually described the chemical reactivity of the molecule. In the present study, $\Delta \mathrm{E}_{\mathrm{gap}}$ is found to be $2.42 \mathrm{eV}$; which indicates the high reactivity of the compound in oxidation reduction reaction. Hence the dye is highly reactive and recommends being use in dye sensitized solar cell (DSSC). The ionization potential I and electron affinity $\mathrm{A}$ are so important parameters. The determination of these two important parameters allows the calculation of the global reactivity descriptors. The A and I parameters depend mainly on the one-electron HOMO and LUMO orbital energy values. The molecule of less I value will be the better electron donor; while the molecule of high I value will be the better electron acceptor. From Table 5, it has $1.72 \mathrm{eV}$ value of $\mathrm{I}$ and $\mathrm{A}$ is $-0.7 \mathrm{eV}$ and electronegativity is equal $0.51 \mathrm{eV}$. Figure 5 represents Frontier molecular orbitals of the studied DO-26 dye compounds (D1).
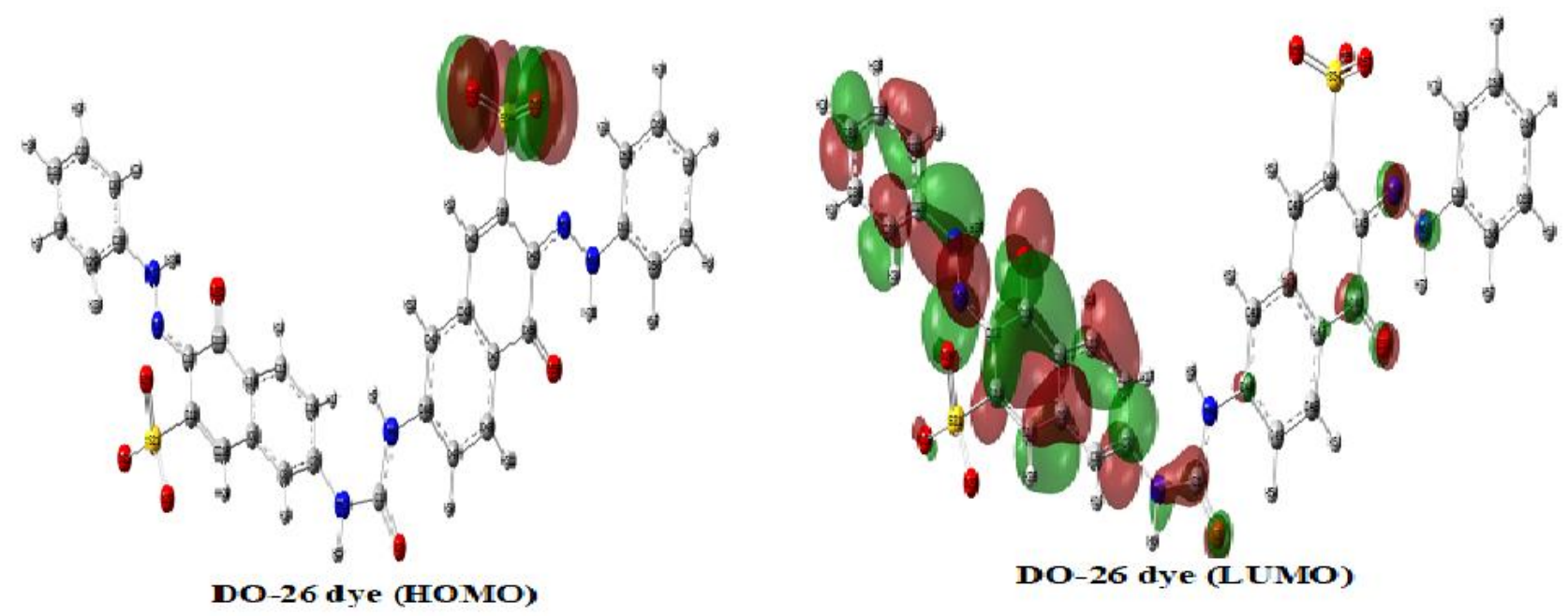

Figure 5. Frontier molecular orbitals of the studied DO-26 dye compounds (D1)

Figure 5, shows that the dispersion of charge densities of HOMOs and LUMOs indicates charge transfer to naphthalene with azo-phenyl ring (left arm of urea derivatives) from $\mathrm{SO}_{3}$ group of right arm. The dipole moment vector is representing the direction of the electronic charge transfer motion and it equals $10.98 \mathrm{D}$.

\subsubsection{Global reactivity descriptors of D1}

The nature of chemical interactions and chemical reactivity of atoms, ions or molecules are considered important to explain the reactivity of the molecular dye DO-26 (D1). The CDFT, quantum chemical descriptors like chemical hardness $(\eta)$, electronic chemical potential $(\mu)$, and electronegativity $(\chi)$ are related to the electron number $(\mathrm{N})$ at constant external potential, $v(\mathrm{r})$, respectively [49-51] and expressed by the following equations (1 and 2). 


$$
\begin{aligned}
& \mu=\left(\frac{\partial E}{\partial N}\right)_{v(r)} \\
& \eta=\frac{1}{2}\left(\frac{\partial^{2} E}{\partial N^{2}}\right)_{v(r)}=\frac{1}{2}\left(\frac{\partial \mu}{\partial N}\right)_{v(r)}
\end{aligned}
$$

Also, Global electrophilicity index ( $\omega)$, Global softness $(S)$ and electronegativity $(\chi)$ are computed based on HOMO and LUMO energy values for D1 using B3LYP/ 6-311++G(d,p) theory level of calculation $[49,50]$ as computed by application of equations (3-6):

$$
\begin{aligned}
& \eta=\left(E_{\text {HомO }}-E_{\text {LUMO }}\right) / 2 \\
& \mu=-\frac{E_{\text {HOMO }}+E_{\text {LUMO }}}{2}=-\chi \\
& \omega=\mu^{2} / 2 \eta \\
& \chi=\left(E_{\text {HOMO }}+E_{L U M O}\right) / 2 \\
& S=1 / 2 \eta
\end{aligned}
$$

The computed GRD reactivity descriptors of the compound D1 are represented in Table 5. These data have been considered very important to explain the reactivity and stability of studied DO-26 (D1). D1 has t value of $\eta=1.21 \mathrm{eV}$ of chemical hardness and the softness value $(0.41 \mathrm{eV})$; which indicates softness and chemical reactivity of studied. The results obtained are in good correlation with the find HOMO-LUMO band energy gaps of the synthesized dye. The calculated chemical potential $(\mu)$ value of the studied dye DO-26 (D1) presented in Table 5 means it has high chemical potential value $(-0.5 \mathrm{eV})$; which refers to the high charge transfer occurs within tested dye.

The electrophilicity index $(\omega)$ is a thermodynamic parameter that measures energy changes in a chemical system saturated by adding electrons. It described the chemical reactivity of a system. The calculated data presented in Table 5 proved that D1 has Electrophilicity index value $(\omega=0.11$ $\mathrm{eV}$ ) and the Nueclophilicity index $(\mathrm{N})$ is equals $+2.49 \mathrm{eV}$. These values indicate that the dye favor nucleophilic approximate 23 times more than electrophilic. Compound D1 possesses electronegativity $(\mathrm{X})$, value of $0.51 \mathrm{eV}$ as a measure for tendency of molecule to attract electrons means it has high softness values $(0.51 \mathrm{eV})$ and showed high reactivity,

\subsubsection{Local reactivity descriptor of D1}

To understand the chemical reactivity and site selectivity of theoretically tested compounds; it is very important to use the concepts of local and global reactivity descriptors $[52,53]$. The Fukui function is the first derivative of the electronic density $\rho(\mathrm{r})$ of a system with respect to the number of electrons (N) at a fixed external potential $v(r)$ as defined by Yang and Mortier (1986) [54]. It has been used to analyze local molecular site selectivity of the molecules as given by Equation 8 : 


$$
f(r)=\left(\frac{\partial \rho(r)}{\partial N}\right)_{v(r)}=\frac{1}{2}\left(\frac{\partial \mu}{\partial v(r)}\right)_{v(r)}
$$

The local descriptors such as electrophilic and nucleophilic Fukui functions had been more clarified by Parr and Yang $[55,56]$. The calculation of Fukui functions is very important to determine the active sites of the DO-26 dye (D1). It mainly based calculation of the electronic density changes occurred during the molecule reactions. Usually Fukui functions $f^{+}(\mathrm{r}), f^{-}(\mathrm{r})$ and $f^{0}$ (r) are essentially calculated in three chemical situations such as electrophilic, nucleophilic and radical attacks using the following equations as [53, 56-58]:

$f^{-}(\mathrm{r})=\mathrm{q}_{\mathrm{k}}(\mathrm{N})-\mathrm{q}_{\mathrm{k}}(\mathrm{N}-1) \approx \rho^{\mathrm{HOMO}}(\mathrm{r})$ for electrophilic attack

$f^{+}(\mathrm{r})=\mathrm{q}_{\mathrm{k}}(\mathrm{N}+1)-\mathrm{q}_{\mathrm{k}}(\mathrm{N}) \approx \rho^{\mathrm{LUMO}}(\mathrm{r})$ for nucleophilic attack $f^{0}(\mathrm{r})=\frac{1}{2}\left[\mathrm{q}_{\mathrm{k}}(\mathrm{N}+1)-\mathrm{q}_{\mathrm{k}}(\mathrm{N}-1)\right] \approx \frac{1}{2}\left[\rho^{\mathrm{HOMO}}(\mathrm{r})+\rho^{\mathrm{LUMO}}(\mathrm{r})\right] \quad$ for Radical attack Where $\mathrm{q}_{\mathrm{k}}(\mathrm{N}), \mathrm{q}_{\mathrm{k}}(\mathrm{N}+1)$ and $\mathrm{q}_{\mathrm{k}}(\mathrm{N}-1)$ are the atomic population on the $k_{t h}$ atom for the neutral molecule, its anionic and cationic species respectively. Chattaraj et al. [59] defined the local quantity called philicity $\omega_{k}^{\alpha}$ associated with a site $\mathrm{k}$ in a molecule with the assistance of corresponding condensed-to-atom variants of Fukui function, $f_{k}^{\alpha}$ as in Equation (9).

$$
\omega_{k}^{\alpha}=\omega f_{k}^{\alpha}
$$

Where $\alpha=+,-$ and 0 correspond to local philic quantities describing nucleophilic, electrophilic and radical attacks, respectively. The highest $\omega_{k}^{\alpha}$ corresponds to the most electrophilic site in a molecule. Softness $s_{k}^{\alpha}$ describe the reactivity of atoms in molecules had been proposed by Lee et al. [20, 59] and expressed by Equation (10).

$$
s_{k}^{\alpha}=s f_{k}^{\alpha}
$$

, Morell and Labbe et al [60] proposed another Dual descriptor $(\Delta f(\mathrm{r}))$ concerning electrophilic and nucleophilic capacity of a given atomic site in the molecule which is given by:

$$
\Delta f(\mathrm{r})=f^{+}(\mathrm{r})-f^{-}(\mathrm{r})
$$

Where $\Delta f(\mathrm{r})$ is the difference between the nucleophilic and electrophilic Fukui function. If $\Delta f(\mathrm{r})>0$ refers to nucleophilic attack. If $\Delta f(\mathrm{r})<0$ it may be favored for an electrophilic attack. The calculated data using the above equations at the level B3LYP/6-311++G (d,p) for Fukui functions indices, dual descriptor, condensed local softness, local and relative electrophilicity of DO-26 are given in Tables 6-7.

The values of Fukui functions $f^{-}(\mathrm{r})$ and $f^{+}(\mathrm{r})$ are presented in Table 6 . 
Table 6. Values of the Fukui functions and Dual descriptor of DO-26 dye (D1) using B3lyp/6$311++G(d, p)$.

From these data; it can be stated that the most electrophilic active sites in DO-26 molecule is located on O55, O56 and O57. Likewise, the active sites susceptible for nucleophilic attacks in the same dye are C7, C9, C10, C11, O25, N26, N27, N59 and N60. The same conclusion can be reached considering the Dual descriptor $\Delta f(\mathrm{r})$ regarding electrophilic and nucleophilic attack, also from the philicity indices Table (7).

Table 7. Values of the Condensed local Softnesses (Hartre**e), relative electrophilicity /nucleophilicity (dimensionless) and the Condensed local electrophilicity (ElectroP)/nucleophilicity (NucleoP) index (e*eV) of DO-26 dye (D1) using B3lyp/6$311++G(d, p)$.

The characteristic differences between the calculated values of parameters is mainly attributed the redistribution of electron density inside molecules due to high electronegativity of $\mathrm{N}$ and $\mathrm{O}$ atoms in skeleton, also the effect of $-\mathrm{C}=\mathrm{O} \ldots \mathrm{HN},-\mathrm{SO}_{3}{ }^{-1}$ groups. The obtained results of the calculated functions are in good agreement with the last population analysis and computed HOMO and LUMO energies.

By using implemented code in Multi wave function v3.8 software program [37]; condensed local softness, local electrophilicity /Nueclophilicity index, and relative electrophilicity/Nueclophilicity have been also calculated for each atom in the studied molecule from CDFT point of view to complete the picture of the studied dye map. The careful inspection of these data revealed that; the dye molecule had the donation and the back-donation processes at their active center (O55, O56, O57, C7, C9, C10, C11, O25, N26, N27, N59 and N60); which is in good agreement with the Fukui functions data. It also agreed well with the obtained frontier orbital results represented in Tables (6-7).

According to these results, one can conclude that the studied dye possess lot of active centers to interact with pocket protein surface, through donating electrons to orbitals and back donation process. The calculated local descriptors data revealed that the theoretical variation efficiencies of the investigative molecules agree well with the available experimental data in the same work.

\subsubsection{Molecular electrostatic potential map (MEP)}

Electrostatic potential (ESP) on molecular van der Waals surfaces have emerged as powerful tools in predicting, interpreting, and rationalizing trends in different areas of chemistry [61] as well as in drug design and molecular biology [62]. ESP-mapped surfaces are related to the electronic 
density. Hence they are very useful descriptors for illustrating the charge distributions atoms of the molecules, visualizing variably charged regions on its surface. Therefore ESP determines most probable sites for electrophilic attack and nucleophilic reactions as well as hydrogen-bonding interactions in the molecule [62]. ESPs are usually used for studying and predicting intermolecular interaction [63]. The ESPs of studied compounds is very helpful in understanding their important interactions with biological receptors.

The negative ESPs values means attractive interaction of test charges; while positive ESPs values indicate repulsion. The electrostatic potential $\mathrm{V}(\mathrm{r})$ (in a.u.) at a given point $\mathrm{r}(\mathrm{x}, \mathrm{y}, \mathrm{z})$ is defined in terms of the interaction energy between the electrical charges generated from electrons the molecule and nuclei positive proton located. The electrostatic potential V(r) (in a.u.) is given by the equation (12)

$$
V(r)=\sum_{A}^{n u c l e i} \frac{Z_{A}}{\left|R_{A}-r\right|}-\int \frac{\rho\left(r^{\prime}\right)}{\left|r-r^{\prime}\right|} d r^{\prime}
$$

$\boldsymbol{Z}_{\boldsymbol{A}}$ and $\boldsymbol{R}_{\mathbf{A}}$ are the charge and position of nucleus $\mathrm{A}$, and $\rho\left(\mathbf{r}^{\prime}\right)$ is the electron density at position $\mathbf{r}^{\prime}$, all in atomic units. ESP-mapped surfaces of the studied compound, D1 are shown in Figure 6.

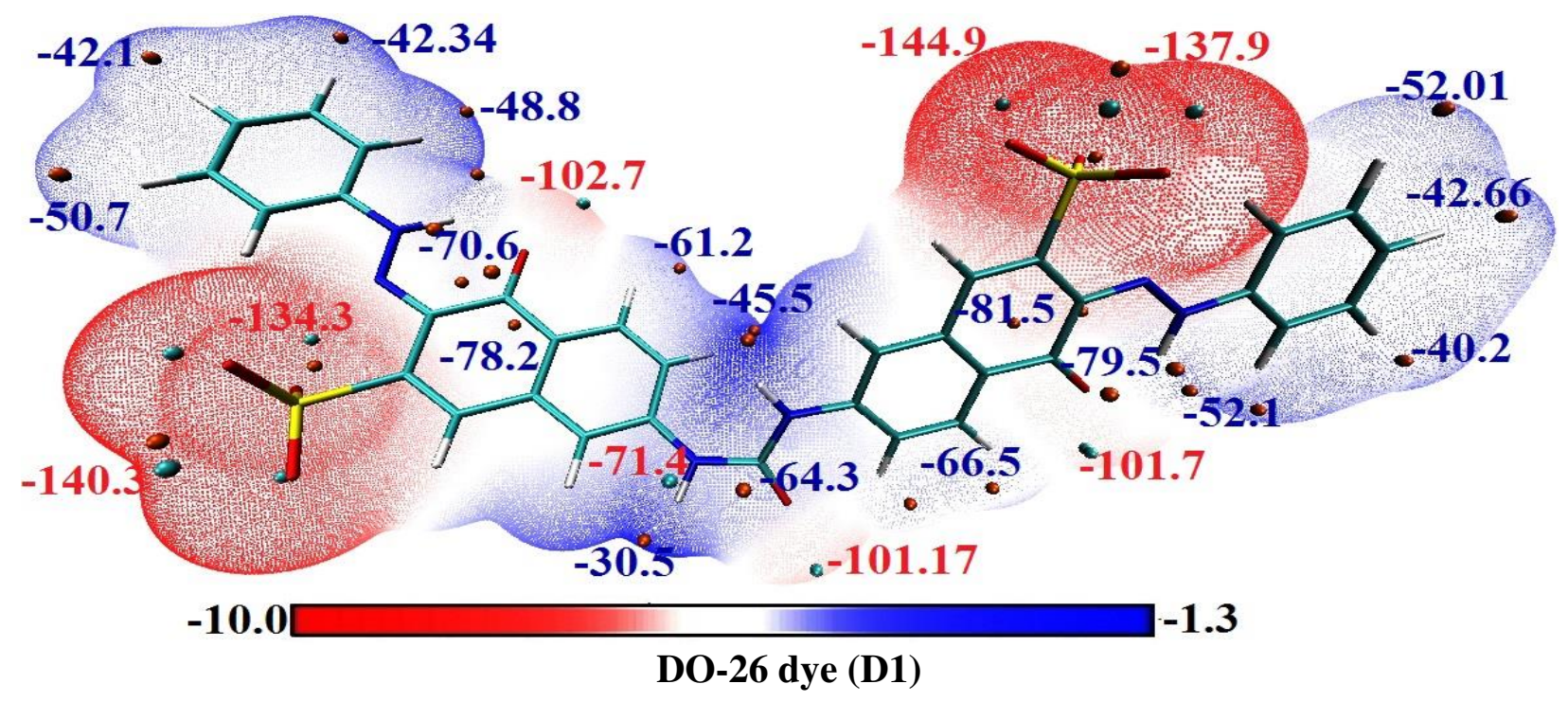

Fig. 6. ESP-mapped surfaces of the synthesized DO-26 dye compound (D1)

Module of Multi wave function program is used for the quantitative molecular surface analysis and it is capable of partitioning the whole van der Waals surface into multiple fragments. It also allows discussion of the characteristics of the ESP distribution of studied dye D1. 
The surface of DO-26 (D1) exhibits large negative value of ESP around the -SO3- groups ($144.9,-140.3 \mathrm{kcal} / \mathrm{mol}) . \mathrm{C} 13=\mathrm{O} 25 \ldots \mathrm{H} 39 \mathrm{~N} 27$ and $\mathrm{C} 46=\mathrm{O} 58 \ldots \mathrm{H} 72 \mathrm{~N} 60 \quad(-101.7$ and 102.7 $\mathrm{kcal} / \mathrm{mol}$ ) with spreading the negative charge on different active sites.

As the electron redistribution ability of the different chelation D1 the global minima of ESPs and the global maxima of ESPs on the surfaces of the studied compounds are localized. This means that the expected interactions of dye D1 with a target protein will be mostly polar (electrostatic or hydrogen bonding) via the most reactive centers. Careful inspection of these ESPs values confirms on the ability to induce intra-molecular charge transfer (ICT) and hydrogen bond interaction, hence can act as drug. It can be asserted on the basis of ESP-mapped, that an electrophile is attracted towards negative region of diazonium and urea center fragment with -SO3- while a nucleophilic attack favors the electropositive region. These values indicate the same results from NPA and local reactivity descriptors analysis mentioned in above sections.

\subsubsection{Electronic absorption spectra}

Direct orange 26 dye (D1) has been synthesized and confirmed to possess antibacterial and application in printing and dyeing [64]. No correlation between experimental and calculated TDDFT UV/Vis spectra for DO-26 (D1) had been previously published elsewhere. To analyze how the UV-Visible spectrum of D1 is varied, the experimental absorption electronic spectra in water solvent and computed are depicted in Figure 7. The calculated absorption maximum wavelengths $\left(\lambda_{\max }\right)$, electronic excitation energies $(\Delta \mathrm{E})$, and oscillator strengths $(f)$ of $\mathrm{D} 1$ in water are given in Table 8 together with the corresponding experimental values.

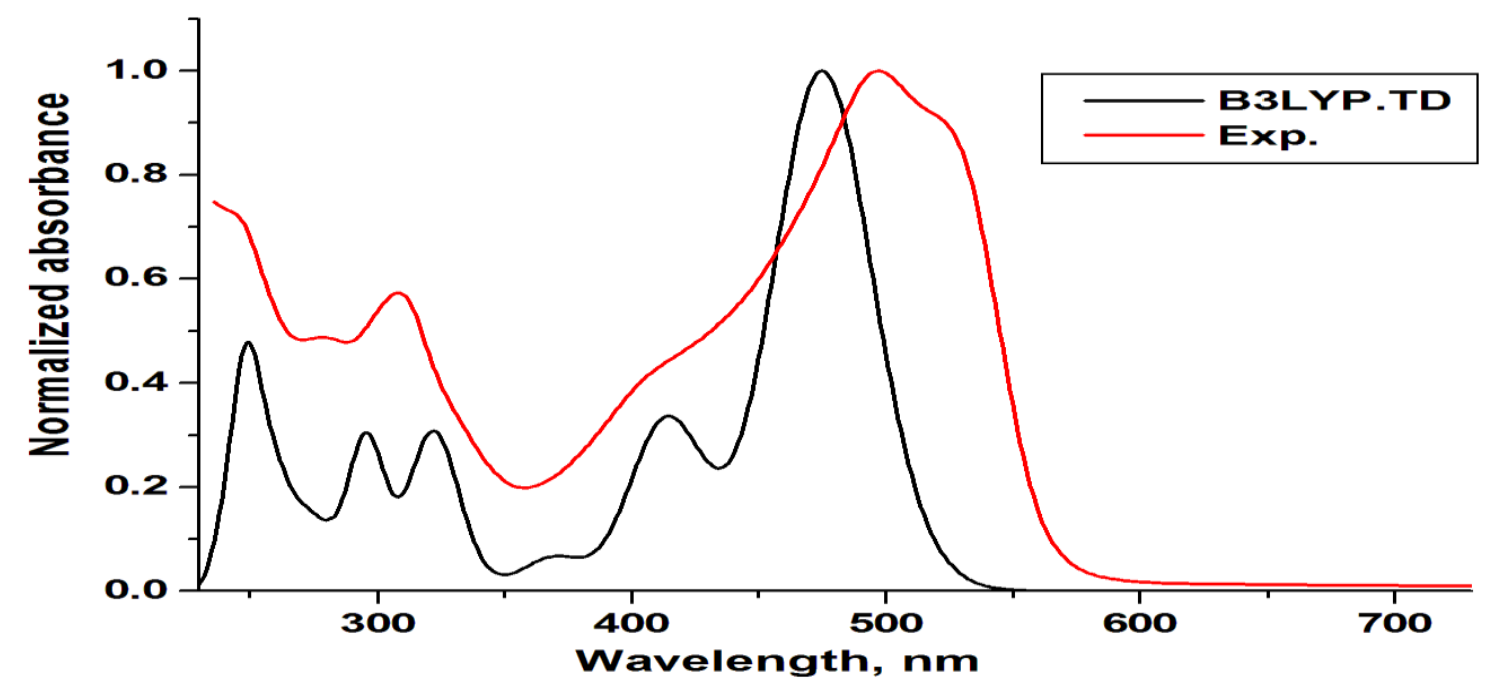

Figure 7: Experimental and theoretical UV/Visible spectra of dye (D1) obtained applying the TDPCM-B3LYP (Water) /6-311++G(d,p) under level of approximation. 
Table 8: UV spectra parameters that characterized dye D1 in water such as $\left(\lambda_{\max }\right)$, electronic excitation energies $(\Delta \mathrm{E})$, and oscillator strengths $(f)$; both theoretical and experimental data

\begin{tabular}{|c|c|c|c|c|c|c|c|}
\hline & \multicolumn{2}{|r|}{$\lambda_{\max }(\mathbf{n m})$} & \multirow{2}{*}{$\frac{\varepsilon\left(\mathrm{mol}^{-1} \cdot \mathrm{cm}^{-1} \cdot \mathrm{L}\right)}{\operatorname{Exp} .}$} & \multirow{2}{*}{$f$} & \multicolumn{2}{|c|}{$\Delta E(\mathrm{eV})$} & \multirow{2}{*}{$\begin{array}{c}\text { Transition } \\
\text { assignment }\end{array}$} \\
\hline & Exp. & TD-DFT & & & Exp. & TD-DFT & \\
\hline $\mathbf{S}_{\mathbf{0}} \rightarrow \mathbf{S}_{\mathbf{1}}$ & 511 & $475(\mathrm{H} \rightarrow \mathrm{L}(0.5403))$ & 13,395 & 1.19 & 2.43 & 2.61 & $\pi \rightarrow \pi^{*}$ \\
\hline $\mathbf{S}_{\mathbf{0}} \rightarrow \mathbf{S}_{2}$ & 491 & $466(\mathrm{H}-1 \rightarrow \mathrm{L}(0.584))$ & 14,514 & 0.25 & 2.53 & 2.66 & $\pi \rightarrow \pi^{*}$ \\
\hline $\mathbf{S}_{\mathbf{0}} \rightarrow \mathbf{S}_{\mathbf{3}}$ & 416 & $412(\mathrm{H}-2 \rightarrow \mathrm{L}(0.629))$ & 6,777 & 0.44 & 2.98 & 3.00 & $\pi \rightarrow \pi^{*}$ \\
\hline $\mathbf{S}_{\mathbf{0}} \rightarrow \mathbf{S}_{4}$ & 321 & $319(\mathrm{H}-1 \rightarrow \mathrm{L}+2(0.492))$ & 5,440 & 0.21 & 3.86 & 3.88 & $\pi \rightarrow \pi^{*}$ \\
\hline $\mathbf{S}_{\mathbf{0}} \rightarrow \mathbf{S}_{5}$ & 302 & $303(\mathrm{H} \rightarrow \mathrm{L}+2(0.616))$ & 8,313 & 0.03 & 4.11 & 4.1 & $\pi \rightarrow \pi^{*}$ \\
\hline $\mathbf{S}_{\mathbf{0}} \rightarrow \mathbf{S}_{\mathbf{6}}$ & 272 & $267(\mathrm{H}-12 \rightarrow \mathrm{L}+1(0.239))$ & 7,077 & 0.02 & 4.54 & 4.64 & $\pi \rightarrow \pi^{*}$ \\
\hline
\end{tabular}

These data show six absorption bands with maxima at $511 \mathrm{~nm}\left(\varepsilon=13,395 \mathrm{M}^{-1} \cdot \mathrm{cm}^{-1}\right), 491 \mathrm{~nm}(\varepsilon=$ $\left.14514 \mathrm{M}^{-1} \cdot \mathrm{cm}^{-1}\right), 416 \mathrm{~nm}\left(\varepsilon=14514 \mathrm{M}^{-1} \cdot \mathrm{cm}^{-1}\right), 321 \mathrm{~nm}\left(\varepsilon=6777 \mathrm{M}^{-1} \cdot \mathrm{cm}^{-1}\right), 302 \mathrm{~nm}\left(\varepsilon=5440 \mathrm{M}^{-}\right.$ $\left.{ }^{1} . \mathrm{cm}^{-1}\right)$, and $267 \mathrm{~nm}\left(\varepsilon=7077 \mathrm{M}^{-1} \cdot \mathrm{cm}^{-1}\right)$. Figure 8 Show natural transition orbitals (NTOs) occupied and unoccupied in the electronic transitions between the ground state (S0) and six lowlying singlet excited states (Sn) of DO26 dye (D1).

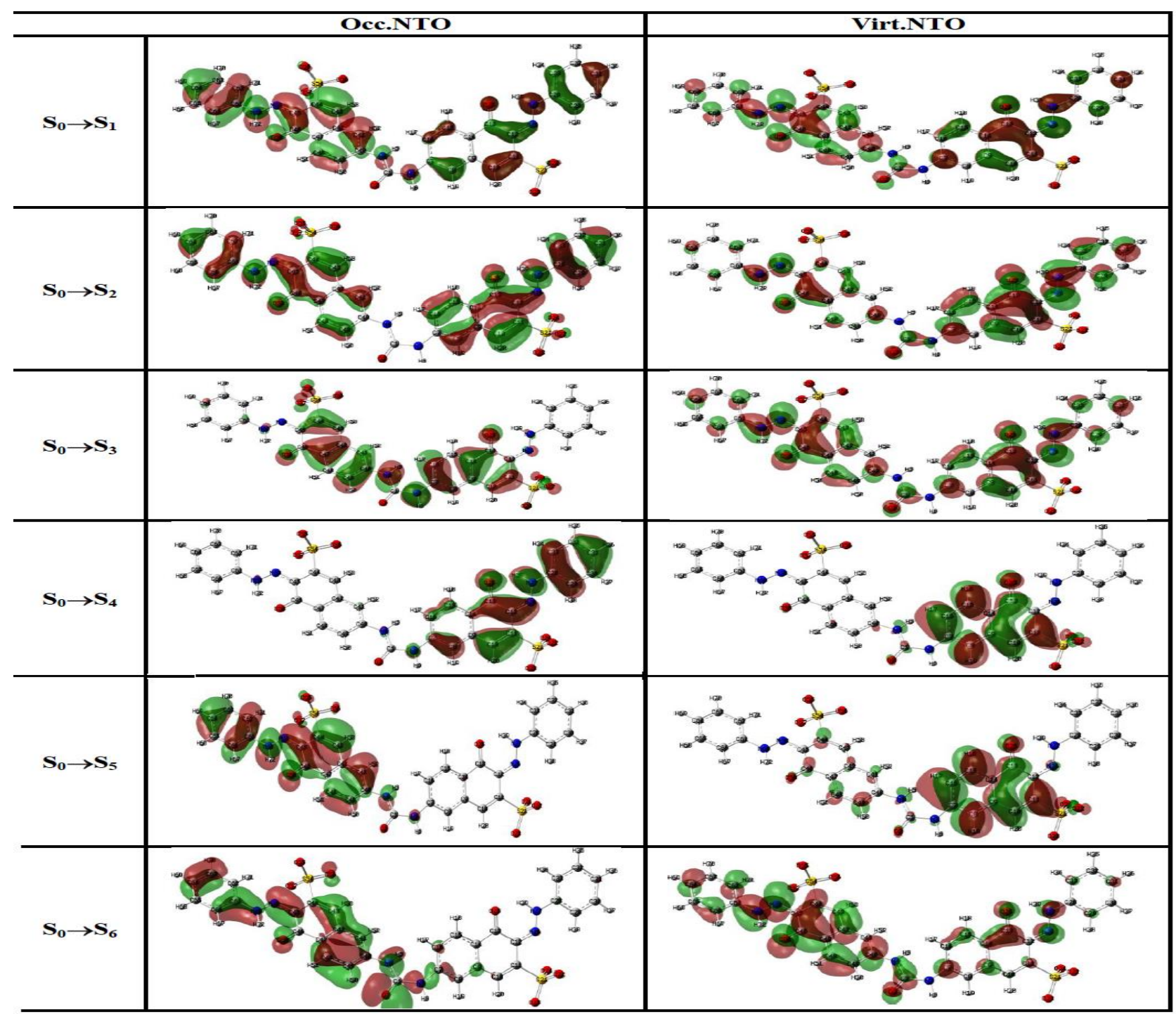


Figure 8: Natural transition orbitals (NTOs) occupied and non-occupied in the electronic transitions between the ground state (S0) and six low-lying singlet excited states (Sn) of DO26 dye (D1) obtained at the PCM-B3LYP (Water) /6-311++G(d,p) level of approximation.

The data obtained in Figure 8 of the computed natural transition orbitals (NTOs) indicate that these electronic transitions can be assigned as $\pi-\pi^{*}$ transitions.

The Hirshfeld population analysis is used to calculate percent contributions of molecular fragments to occupied and unoccupied natural transition orbitals in the electronic transitions between the ground state (S0) and six low-lying singlet excited states ( $\mathrm{Sn}$ ) of D1 obtained at the PCM-B3LYP (Water) /6-311++G(d,p) level of approximation and depicted in Table 9.

Table 9. The electronic transitions between the ground state (S0) and six low-lying singlet excited states (Sn) of D1 obtained at the PCM-B3LYP (Water) /6-311++G(d,p) level of approximation using Hirshfeld population analysis.

\begin{tabular}{|l|l|r|r|r|r|r|r|r|}
\hline & & Urea Center & Napth_R & AzoPh_R & Napth_L & AzoPh_L & Right-arm & Left-arm \\
\hline \multirow{3}{*}{$\mathbf{S}_{\mathbf{0}} \rightarrow \mathbf{S}_{\mathbf{1}}$} & Occ.NTO & 2.61 & 20.08 & 15.06 & 35.24 & 26.63 & 35.15 & 61.87 \\
\cline { 2 - 9 } & Virt.NTO & 3.68 & 29.90 & 21.66 & 25.52 & 18.82 & 51.56 & 44.33 \\
\hline \multirow{3}{*}{$\mathbf{S}_{\mathbf{0}} \rightarrow \mathbf{S}_{\mathbf{2}}$} & Occ.NTO & 0.69 & 35.88 & 22.17 & 24.56 & 16.10 & 58.05 & 40.66 \\
\cline { 2 - 9 } & Virt.NTO & 3.33 & 42.47 & 31.90 & 12.58 & 9.10 & 74.37 & 21.68 \\
\hline \multirow{2}{*}{$\mathbf{S}_{\mathbf{0} \rightarrow \mathbf{S}_{\mathbf{3}}}$} & Occ.NTO & 21.04 & 34.41 & 1.50 & 41.02 & 1.96 & 35.91 & 42.97 \\
\cline { 2 - 9 } & Virt.NTO & 3.69 & 29.82 & 22.12 & 24.88 & 19.04 & 51.95 & 43.92 \\
\hline \multirow{2}{*}{$\mathbf{S}_{\mathbf{0}} \rightarrow \mathbf{S}_{\mathbf{4}}$} & Occ.NTO & 1.22 & 46.73 & 49.27 & 0.89 & 0.56 & 96.00 & 1.44 \\
\cline { 2 - 9 } & Virt.NTO & 3.38 & 93.73 & 0.94 & 1.60 & 0.25 & 94.66 & 1.85 \\
\hline \multirow{2}{*}{$\mathbf{S}_{\mathbf{0} \rightarrow \mathbf{S}_{\mathbf{5}}}$} & Occ.NTO & 2.33 & 1.04 & 0.01 & 55.37 & 41.25 & 1.05 & 96.62 \\
\cline { 2 - 9 } & Virt.NTO & 3.53 & 89.14 & 0.96 & 6.17 & 0.10 & 90.09 & 6.27 \\
\hline \multirow{2}{*}{$\mathbf{S}_{\mathbf{0}} \rightarrow \mathbf{S}_{\mathbf{6}}$} & Occ.NTO & 46.25 & 3.61 & 1.34 & 31.65 & 17.14 & 4.95 & 48.79 \\
\cline { 2 - 9 } & Virt.NTO & 5.27 & 12.39 & 7.42 & 44.02 & 30.75 & 19.81 & 74.77 \\
\hline
\end{tabular}

These data of molecular orbital compositions are essentailly based on the percent contributions of urea center, naphthalene right arm (Napth_R), naphthalene left arm (Napth_L), azo-phenyl right arm (Azoph_R) and azo-phenyl left arm (Azoph_L) molecular fragments to the occupied and virtual NTOs.

The first transition $\left(\mathrm{S}_{0} \rightarrow \mathrm{S}_{1}\right)$, is related to electrons occupied NTO of $\mathrm{p}_{\mathrm{z}}$ and $\mathrm{p}_{\mathrm{x}}$ orbitals that mainly localized on O55, O56 and O57 of the sulfonic group (S54-(O55, O56 and O57) with contributions of $\sim 26 \%, 30 \%$ and $32 \%$, respectively. From these data it is obvious that $\pi$-bonding interaction exists between the $\mathrm{p}_{z}$ orbitals of these atoms. The unoccupied NTO is composed of $\mathrm{p}_{z}$ orbitals mainly localized on $\mathrm{C} 13, \mathrm{O} 25$ and $\mathrm{N} 26$ of the active group in right naphthalene group with contributions of $\sim 10 \%, 9.5 \%$ and $17 \%$, respectively. From these data it is obvious that $\pi^{*}$ antibonding interaction exists between the $\mathrm{p}_{z}$ orbitals of these atoms. It is clear from data in Table 
9 , electron density $\pi \rightarrow \pi^{*}$ transition from left arm to right arm by around $17 \%$ of electron localized over the entire molecule.

The second transition $\left(\mathrm{S}_{0} \rightarrow \mathrm{S}_{2}\right)$, is related to electrons occupied NTO of $\mathrm{p}_{z}, \mathrm{p}_{\mathrm{x}}$ and $\mathrm{p}_{\mathrm{y}}$ orbitals mainly localized on O22, O23 and O24 of the sulphonic group (S21-(O22, O23 and O24) with contributions of $\sim 31 \%, 25 \%$ and $33 \%$, respectively as a result of $\pi$-bonding interaction exists between the p sub-orbitals of these atoms. The non-occupied NTO are composed of $\mathrm{p}_{z}$ orbitals that mainly localized on $\mathrm{C} 13, \mathrm{O} 25$ and $\mathrm{N} 26$ of the active group in right naphthalene group as $\mathrm{S}_{0} \rightarrow \mathrm{S}_{1}$. A $\pi^{*}$-antibonding interaction exists between the $\mathrm{p}_{z}$ orbitals of these atoms is mainly related electron density $\pi \rightarrow \pi^{*}$ transition from left arm to right arm by around $20 \%$ of electron localized over the entire molecule.

For the third transition $\left(\mathrm{S}_{0} \rightarrow \mathrm{S}_{3}\right)$, the occupied NTO the $\pi$-bonding interaction is concentrated between the $\mathrm{p}_{z}$ orbitals of urea center and left naphthalene arm with 22 and 41\%, respectively. The un-occupied NTO is composed of $p_{z}$ orbitals that mainly localized on the right naphthalene group and azo-phenyl with contributions of $\sim 30 \%$ and $23 \%$, respectively. A $\pi^{*}$-antibonding transition may be assigned as $\pi \rightarrow \pi^{*}$.interaction exists between the $\mathrm{p}_{z}$ orbitals of these atoms.

The fourth transition $\left(\mathrm{S}_{0} \rightarrow \mathrm{S}_{1}\right)$, as a result of electrons occupied NTO is mainly localized on right arm group (C7-H39) with contributions of naphthalene group 47\% and azo-phenyl 50\%. The $\pi$-bonding interaction is due to $\pi \rightarrow \pi^{*}$ transition and exists between the $p_{z}$ orbitals of these range atoms. The un-occupied NTO is found to be mainly localized right naphthalene group with contributions of $\sim 94 \%$. It is mainly occurred due to $\pi^{*}$-antibonding interaction exists between the $\mathrm{p}_{\mathrm{z}}$ orbitals of these atoms.

The fifth transition $\left(\mathrm{S}_{0} \rightarrow \mathrm{S}_{5}\right)$, as a result of electrons occupied NTO is mainly localized on left arm of naphthalene and azo-phenyl with contributions of $\sim 56 \%$ and $41 \%$, respectively and attributed to $\pi$-bonding interaction exists between the $\mathrm{p}$ sub-orbitals of these atoms. The nonoccupied NTO is composed of $\mathrm{p}_{z}$ orbitals and mainly localized on right naphthalene group with contribution $\sim 90 \%$. A $\pi^{*}$-antibonding transition may be assigned as $\pi \rightarrow \pi^{*}$ interaction exists between the $\mathrm{p}_{z}$ orbitals of these atoms.

For the $6^{\text {th }}$ transition $\left(\mathrm{S}_{0} \rightarrow \mathrm{S}_{6}\right.$ ), is essentially related to the occupied NTO $\pi$-bonding electron interactions exist between the $\mathrm{p}_{z}$ orbitals of urea center and left naphthalene arm with 47 and $31 \%$. Consequently, the non-occupied NTO is composed of $\mathrm{p}_{z}$ orbitals mainly localized left naphthalene group and azo-phenyl left part with contributions of $\sim 45 \%$ and $31 \%$, respectively; resulting in $\pi^{*}$ antibonding interaction leading to $\pi \rightarrow \pi^{*}$ transition exists between the p orbitals of these atoms.

These detailed discussions are confirmed by Figure 8; which illustrate Natural transition orbitals (NTOs) occupied and unoccupied due to transitions between the ground state (S0) and six low-lying singlet excited states (Sn) of DO26 dye (D1) obtained at the PCM-B3LYP (Water) /6$311++G(d, p)$ level of approximation.. This details discussion clearly shows a $\pi$-bonding interaction 
among the specific groups of atoms as mentioned above. The NTOs data clearly discussed $\pi$ antibonding interactions among all these contributing species. The nature of vertical electronic transitions in the studied compound (D1) is analyzed via determining the topology of the molecular orbitals involved in these transitions. The NTOs of the first electronic transition $(\mathrm{S} 0 \rightarrow \mathrm{S} 1)$, associated with the ICT band, are given in Figure 8. It is noticed that both occupied and virtual NTOs demonstrate the typical $\pi$-type molecular orbital characteristic. They are clearly delocalized over the entire molecule including the two arms. The details of the active space of molecular orbital wave function representation and its surfaces (see the supporting information for details in supplementary Figure S2 and Table S2.

These six transitions and calculated parameters are given in Table 10.

Table 10. Charge transfer $(\mathrm{CT})$ length $(\Delta \mathrm{r})$ and variation in dipole moment $\left(\Delta \mu_{\mathrm{CT}}\right)$ indices of the six electronic excitations for the studied D1 are obtained at the PCM-B3LYP(Water)/6$311++\mathrm{G}(\mathrm{d}, \mathrm{p})$ level of approximation.

\begin{tabular}{l|cccccc} 
& $\mathbf{S}_{\mathbf{0}} \rightarrow \mathbf{S}_{\mathbf{1}}$ & $\mathbf{S}_{\mathbf{0}} \rightarrow \mathbf{S}_{\mathbf{2}}$ & $\mathbf{S}_{\mathbf{0}} \rightarrow \mathbf{S}_{\mathbf{3}}$ & $\mathbf{S}_{\mathbf{0}} \rightarrow \mathbf{S}_{\mathbf{4}}$ & $\mathbf{S}_{\mathbf{0}} \rightarrow \mathbf{S}_{\mathbf{5}}$ & $\mathbf{S}_{\mathbf{0}} \rightarrow \mathbf{S}_{\mathbf{6}}$ \\
\hline$\Delta \boldsymbol{r}(\mathbf{\AA})$ & 7.61 & 5.36 & 4.06 & 3.75 & 9.22 & 4.70 \\
$\Delta \boldsymbol{\mu}_{\mathbf{C T}}$ (a.u.) & 3.34 & 2.12 & 2.94 & 7.10 & 7.10 & 2.17 \\
\hline
\end{tabular}

The data in Tables 9-11 refer to the variation in the electron density distribution of the occupied NTOs as a symmetry reason to the electron-donating or accepted ability of two arms; which considered as a good evidence of the intramolecular charge transfer nature.

In order to study the extent of charge transfer (CT) or charge redistribution during the excitations, the $\Delta \mathrm{r}$ index and variation of dipole moment $(\Delta \mu \mathrm{CT})$ of excited state with respect to ground state are computed for the studied molecules using Multiwfn code [27]. The obtained data are depicted in in Table 10. The $\Delta \mathrm{r}$ index [33] can be considered as a measure of charge transfer (CT) length. It can be used to discriminate between local $(\Delta \mathbf{r} \leq 1.5 \AA)$ and charge transfer $(\Delta \mathbf{r} \geq 2.0$ $\AA$ ) electronic excitations. According to $\Delta \mathrm{r}$ values, it can be seen that the charge transfer character in the six transitions, For D1, $\Delta \mathrm{r}$ has value for $\mathrm{S}_{0} \rightarrow \mathrm{S}_{1}(7.61 \AA), \mathrm{S}_{0} \rightarrow \mathrm{S}_{2}(5.36 \AA), \mathrm{S}_{0} \rightarrow \mathrm{S}_{3}(4.06 \AA)$, $\mathrm{S}_{0} \rightarrow \mathrm{S}_{4}(3.75 \AA), \mathrm{S}_{0} \rightarrow \mathrm{S}_{5}(9.22 \AA)$ and $\mathrm{S}_{0} \rightarrow \mathrm{S}_{6}(4.70 \AA)$ transitions, respectively. We can conclude that all transitions may belong to charge transfer type. The dipole moment change upon excitations $\left(\Delta \mu_{\mathrm{CT}}\right)$ is another important factor to assess their CT behavior. For D1, $\Delta \mu_{\mathrm{CT}}$ has value for $\mathrm{S}_{0} \rightarrow \mathrm{S}_{1}$ (3.34 Debye), $S_{0} \rightarrow S_{2}\left(2.12\right.$ Debye), $S_{0} \rightarrow S_{3}$ (2.94 Debye), $S_{0} \rightarrow S_{4}\left(7.10\right.$ Debye), $S_{0} \rightarrow S_{5}(7.10$ Debye) and $\mathrm{S}_{0} \rightarrow \mathrm{S}_{6}(2.17$ Debye) transitions, respectively. Therefore, it is obvious that the CT 
lengths $(\Delta r)$ and dipole moment change $(\Delta \mu \mathrm{CT})$ of $\mathrm{S}_{0} \rightarrow \mathrm{S}_{1}, \mathrm{~S}_{0} \rightarrow \mathrm{S}_{2}, \mathrm{~S}_{0} \rightarrow \mathrm{S}_{3}, \mathrm{~S}_{0} \rightarrow \mathrm{S}_{4}, \mathrm{~S}_{0} \rightarrow \mathrm{S}_{5}$ and $\mathrm{S}_{0} \rightarrow \mathrm{S}_{6}$ electronic excitations belong to charge transfer type.

\section{Conclusions}

DFT calculations have been carried out on DO-26 dye (D1) applying the B3LYP/6-311G method to study the structure characters and vibrational analysis of the tested dye. Highly interesting correlation had been found between experimental and calculated parameters such as bond lengths and vibrational frequencies. Complete assignment of FTIR spectra vibrational modes of DO-26 (D1) is successfully performed at wavenumber range 400 to $4000 \mathrm{~cm}^{-1}$. The AIM analyses actually revealed the presence of intra-molecular hydrogen bonding within two arms of the dye molecule. The obtained data successfully characterized them as medium and weak interactions. The effect of hydrogen bonding on structure and vibrational properties of the tested dye had been professionally also discussed. NBO analysis, HOMO-LUMO and MESP plots had been used to explain chemical reactivity of DO-26 dye (D1) molecule. Various electronic transition parameters have been calculated which actually provide further description and threw more lights on the chemical reactivity and direction of chemical reactions detected in the behavior of DO-26.

Acknowledgement: Authors acknowledge the support of this research by instruments, chemicals and measurements, and programs of Theoretical Calculations given by the Chemistry, Mathematic Departments at Cairo University, and Egyptian Ministry of Health:

\section{Authors Declarations}

\section{Funding: N/A}

Conflict of Interest: The authors declare that they have no conflicts of interest.

Availability of data and material: It is available in transparent forms.

Code Availability: The Gaussian 09W software package has been used for NBO calculations using NBO 3.1 program implemented in the same program. The Gauss View version 5.0.9 [25] involving Chemcraft version 1.6 package

\section{Authors Contributions:}

Mohamed A. Zayed: Writing the manuscript and revision of all of its contents.

Mahmoud A. Noamaan: Made all theoretical calculations and share paper writing.

Zahraa A. M. Abo-Ayad: : Made all experimental work and share paper writing.

\section{References}

1. Abrahart EN (1977) Dyes and their intermediates

2. Acscci Y (2013) Decolorization of Direct Orange 26 by heterogeneous Fenton oxidation. 
Desalin Water Treat 51:7612-7620

3. Tomczak E, Tosik P (2014) Sorption Equilibrium of Azo Dyes Direct Orange 26 and Reactive Blue 81 onto a Cheap Plant Sorbent/Równowaga Sorpcji Barwników Azowych Direct Orange 26 I Reactive Blue $81 \mathrm{Na}$ Tanim Sorbencie Roślinnym. Ecol Chem Eng S $21: 435-445$

4. Kaushik CP, Tuteja R, Kaushik N, Sharma JK (2009) Minimization of organic chemical load in direct dyes effluent using low cost adsorbents. Chem Eng J 155:234-240

5. Ghoreishi SM, Behpour M, Farsani AG (2007) Study of interaction between a cationic surfactant and two anionic azo dyes by ion-selective electrode technique and spectrophotometry. Dye Pigment 74:585-589

6. Ji F, Li C, Zhang J, Deng L (2011) Efficient decolorization of dye pollutants with LiFe (WO4) 2 as a reusable heterogeneous Fenton-like catalyst. Desalination 269:284-290

7. Sert Y, Ucun F (2013) Vibrational spectroscopic investigation of p-, m-and onitrobenzonitrile by using Hartree--Fock and density functional theory. Indian J Phys $87: 809-818$

8. Sert Y, Ucun F, Böyükata M (2013) Vibrational spectroscopic studies of 3hydroxyphenylboronic acid: molecular structure. Indian J Phys 87:113-119

9. Jeffrey GA, Saenger W (2012) Hydrogen bonding in biological structures. Springer Science \& Business Media

10. Barder R (1990) Atoms in molecules: a quantum theory

11. Jabłonski M, Palusiak M (2010) Basis set and method dependence in atoms in molecules calculations. J Phys Chem A 114:2240-2244

12. Jissy AK, Konar S, Datta A (2013) Molecular switching behavior in isosteric DNA base pairs. ChemPhysChem 14:1219-1226

13. Abraham SA, Jose D, Datta A (2012) Do Cation ... $\pi$ Interactions Always Need to be 1:1? ChemPhysChem 13:695-698

14. Frisch MJ, Trucks GW, Schlegel HB, et al (2010) Gaussian 09, Revis. C. 01

15. McLean AD, Chandler GS (1980) Contracted Gaussian basis sets for molecular calculations. I. Second row atoms, $Z=11--18$. J Chem Phys 72:5639-5648

16. Ditchfield R, Hehre WJ, Pople JA (1971) Self-consistent molecular-orbital methods. IX. An extended Gaussian-type basis for molecular-orbital studies of organic molecules. J Chem Phys 54:724-728

17. Becke AD (1988) Density-functional exchange-energy approximation with correct asymptotic behavior. Phys Rev A 38:3098

18. Becke AD (1993) Becke's three parameter hybrid method using the LYP correlation functional. J Chem Phys 98:5648-5652 
19. Johnson BG, Frisch MJ (1993) Analytic second derivatives of the gradient-corrected density functional energy. Effect of quadrature weight derivatives. Chem Phys Lett 216:133-140

20. Lee C, Yang W, Parr RG (1988) Development of the Colle-Salvetti correlation-energy formula into a functional of the electron density. Phys Rev, vol B 37:785-789

21. Ulic SE, Vedova CO Della, Hermann A, et al (2008) Preparation and Properties of Trifluorothioacetic Acid-S-(trifluoromethyl) ester, CF 3C (O) SCF 3. J Phys Chem A 112:6211-6216

22. Reed AE, Weinhold F (1983) Natural bond orbital analysis of near-Hartree--Fock water dimer. J Chem Phys 78:4066-4073

23. Xu X, Truhlar DG (2011) Accuracy of effective core potentials and basis sets for density functional calculations, including relativistic effects, as illustrated by calculations on arsenic compounds. J Chem Theory Comput 7:2766-2779

24. Khan SA, Rizwan K, Shahid S, et al (2020) Synthesis, DFT, computational exploration of chemical reactivity, molecular docking studies of novel formazan metal complexes and their biological applications. Appl Organomet Chem 34:e5444

25. Dennington R, Keith T, Millam J (2009) GaussView, version 5. Semichem Inc Shawnee Mission KS

26. Andrienko GA (2018) Chemcraf program, https://www.chemcraftprog.com

27. Lu T, Chen F (2012) Multiwfn: a multifunctional wavefunction analyzer. J Comput Chem $33: 580-592$

28. Runge E, Gross EKU (1984) Density-functional theory for time-dependent systems. Phys Rev Lett 52:997-1000

29. Miertuš S, Scrocco E, Tomasi J (1981) Electrostatic interaction of a solute with a continuum. A direct utilizaion of $\mathrm{AB}$ initio molecular potentials for the prevision of solvent effects. Chem Phys 55:117-129

30. Miertus S, Tomasi J (1982) Approximate evaluations of the electrostatic free energy and internal energy changes in solution processes. Chem Phys 65:239-245

31. Martin RL (2003) Natural transition orbitals. J Chem Phys 118:4775-4777

32. Guido CA, Cortona P, Mennucci B, Adamo C (2013) On the metric of charge transfer molecular excitations: a simple chemical descriptor. J Chem Theory Comput 9:3118-3126

33. Humphrey W, Dalke A, Schulten K (1996) VMD: visual molecular dynamics. J Mol Graph $14: 33-38$

34. Teixeira F, Cordeiro MNDS (2018) Improving vibrational mode interpretation using bayesian regression. J Chem Theory Comput 15:456-470

35. Teixeira F (2019) Tools for performing vibrational analysis on molecular systems. Version 122 
36. Jamróz MH (2013) Vibrational Energy Distribution Analysis (VEDA): Scopes and limitations. Spectrochim Acta Part A Mol Biomol Spectrosc 114:220-230. https://doi.org/https://doi.org/10.1016/j.saa.2013.05.096

37. Yeo L, Harris KDM (1999) Temperature-dependent structural properties of a solid urea inclusion compound containing chiral guest molecules: 2-bromotetradecane/urea. Can J Chem 77:2105-2118

38. Custelcean R (2008) Crystal engineering with urea and thiourea hydrogen-bonding groups. Chem Commun 295-307

39. Koch U, Popelier PLA (1995) Characterization of CHO hydrogen bonds on the basis of the charge density. J Phys Chem 99:9747-9754

40. Rozas I, Alkorta I, Elguero J (2000) Behavior of ylides containing N, O, and C atoms as hydrogen bond acceptors. J Am Chem Soc 122:11154-11161

41. Rajith L, Jissy AK, Kumar KG, Datta A (2011) Mechanistic study for the facile oxidation of trimethoprim on a manganese porphyrin incorporated glassy carbon electrode. J Phys Chem C 115:21858-21864

42. Jose D, Datta A (2011) Role of multicentered bonding in controlling magnetic interactions in \$ $\$$-stacked bis-dithiazolyl radical. Cryst Growth Des 11:3137-3140

43. Espinosa E, Molins E, Lecomte C (1998) Hydrogen bond strengths revealed by topological analyses of experimentally observed electron densities. Chem Phys Lett 285:170-173

44. Steiner T (2002) The hydrogen bond in the solid state. Angew Chemie Int Ed 41:48-76

45. Emamian S, Lu T, Kruse H, Emamian H (2019) Exploring Nature and Predicting Strength of Hydrogen Bonds: A Correlation Analysis Between Atoms-in-Molecules Descriptors, Binding Energies, and Energy Components of Symmetry-Adapted Perturbation Theory. $\mathbf{J}$ Comput Chem 40:2868-2881

46. Alecu IM, Zheng J, Zhao Y, Truhlar DG (2010) Computational thermochemistry: scale factor databases and scale factors for vibrational frequencies obtained from electronic model chemistries. J Chem Theory Comput 6:2872-2887

47. Silverstein RM, Bassler GC (1962) Spectrometric identification of organic compounds. J Chem Educ 39:546

48. Badawi HM (2007) Vibrational spectra and analysis of acetohydrazide CH3--CO--NH-NH2. Spectrochim Acta Part A Mol Biomol Spectrosc 67:592-597

49. Pearson RG (1986) Absolute electronegativity and hardness correlated with molecular orbital theory. Proc Natl Acad Sci 83:8440-8441

50. Chandra AK, Uchimara T (2001) NLO and NBO analysis of Sarcosine-maleic acid by using HF and B3LYP calculations. J Phys Chem A 105:3578-3582

51. Liu S-B (2009) Conceptual density functional theory and some recent developments. Acta 
Physico-Chimica Sin 25:590-600

52. Geerlings P, De Proft F, Langenaeker W (2003) Conceptual density functional theory. Chem Rev 103:1793-1874

53. Chattaraj PK, Roy DR (2007) Update 1 of: electrophilicity index. Chem Rev 107:PR46-PR74

54. Chattaraj PK, Giri S (2007) Stability, reactivity, and aromaticity of compounds of a multivalent superatom. J Phys Chem A 111:11116-11121

55. Yang W, Mortier WJ (1986) The use of global and local molecular parameters for the analysis of the gas-phase basicity of amines. J Am Chem Soc 108:5708-5711

56. Parr RG, Yang W (1984) Density functional approach to the frontier-electron theory of chemical reactivity. J Am Chem Soc 106:4049-4050

57. Parr RG, Pearson RG (1983) Absolute hardness: companion parameter to absolute electronegativity. J Am Chem Soc 105:7512-7516

58. Contreras RR, Fuentealba P, Galvan M, Perez P (1999) A direct evaluation of regional Fukui functions in molecules. Chem Phys Lett 304:405-413

59. Parthasarathi R, Padmanabhan J, Elango M, et al (2004) Intermolecular reactivity through the generalized philicity concept. Chem Phys Lett 394:225-230

60. Morell C, Grand A, Toro-Labbe A (2005) New dual descriptor for chemical reactivity. J Phys Chem A 109:205-212

61. Naray-Szabo G, Ferenczy GG (1995) Molecular electrostatics. Chem Rev 95:829-847

62. Luque FJ, Lopez JM, Orozco M (2000) Perspective on "Electrostatic interactions of a solute with a continuum. A direct utilization of ab initio molecular potentials for the prevision of solvent effects." Theor Chem Acc 103:343-345

63. Murray JS, Politzer P (2011) The electrostatic potential: an overview. Wiley Interdiscip Rev Comput Mol Sci 1:153-163

64. Zhang Yaomou; Shan ZOMZCDG (2019) Antibacterial wastewater flocculant and its preparation method and application in printing and dyeing wastewater treatment. South China Agric Univ Peop Rep China 
Table 1. The selected bond length $\left(\mathrm{A}^{\circ}\right)$, bond angles and dihedral angles, (degree) of DO-26 dye (D1) at B3lyp/6-311++G(d,p) level of theory.

\begin{tabular}{|c|c|c|c|c|c|}
\hline Coordinate & Value & Coordinate & Value & Coordinate & Value \\
\hline $\mathrm{R}(\mathrm{C} 1, \mathrm{O} 2)$ & 1.223 & $\mathrm{~A}(\mathrm{~N} 3, \mathrm{C} 7, \mathrm{C} 8)$ & 117.64 & $\mathrm{D}(\mathrm{O} 2, \mathrm{C} 1, \mathrm{~N} 4, \mathrm{C} 40)$ & 5.74 \\
\hline $\mathrm{R}(\mathrm{C} 1, \mathrm{~N} 3)$ & 1.393 & $\mathrm{~A}(\mathrm{~N} 3, \mathrm{C} 7, \mathrm{C} 16)$ & 122.81 & $\mathrm{D}(\mathrm{N} 3, \mathrm{C} 1, \mathrm{~N} 4, \mathrm{C} 40)$ & -175.86 \\
\hline $\mathrm{R}(\mathrm{C} 1, \mathrm{~N} 4)$ & 1.377 & $\mathrm{~A}(\mathrm{C} 8, \mathrm{C} 7, \mathrm{C} 16)$ & 119.44 & $\mathrm{D}(\mathrm{C} 1, \mathrm{~N} 3, \mathrm{C} 7, \mathrm{C} 8)$ & -151.94 \\
\hline $\mathrm{R}(\mathrm{N} 3, \mathrm{H} 6)$ & 1.010 & $\mathrm{~A}(\mathrm{C} 7, \mathrm{C} 8, \mathrm{C} 9)$ & 121.67 & $\mathrm{D}(\mathrm{C} 1, \mathrm{~N} 3, \mathrm{C} 7, \mathrm{C} 16)$ & 31.98 \\
\hline $\mathrm{R}(\mathrm{N} 3, \mathrm{C} 7)$ & 1.411 & $\mathrm{~A}(\mathrm{C} 12, \mathrm{C} 11, \mathrm{~S} 21)$ & 121.12 & $\mathrm{D}(\mathrm{C} 1, \mathrm{~N} 4, \mathrm{C} 40, \mathrm{C} 41)$ & -174.24 \\
\hline $\mathrm{R}(\mathrm{N} 4, \mathrm{H} 5)$ & 1.010 & $\mathrm{~A}(\mathrm{C} 11, \mathrm{C} 12, \mathrm{C} 13)$ & 120.19 & $\mathrm{D}(\mathrm{C} 1, \mathrm{~N} 4, \mathrm{C} 40, \mathrm{C} 49)$ & 6.93 \\
\hline $\mathrm{R}(\mathrm{N} 4, \mathrm{C} 40)$ & 1.411 & $\mathrm{~A}(\mathrm{C} 11, \mathrm{C} 12, \mathrm{~N} 26)$ & 116.82 & $\mathrm{D}(\mathrm{N} 3, \mathrm{C} 7, \mathrm{C} 8, \mathrm{C} 9)$ & -175.75 \\
\hline $\mathrm{R}(\mathrm{C} 11, \mathrm{C} 12)$ & 1.454 & $\mathrm{~A}(\mathrm{C} 13, \mathrm{C} 12, \mathrm{~N} 26)$ & 122.99 & $\mathrm{D}(\mathrm{C} 8, \mathrm{C} 9, \mathrm{C} 10, \mathrm{C} 11)$ & -179.19 \\
\hline $\mathrm{R}(\mathrm{C} 11, \mathrm{~S} 21)$ & 1.851 & $\mathrm{~A}(\mathrm{C} 12, \mathrm{C} 13, \mathrm{C} 14)$ & 117.12 & $\mathrm{D}(\mathrm{C} 8, \mathrm{C} 9, \mathrm{C} 14, \mathrm{C} 13)$ & -179.99 \\
\hline $\mathrm{R}(\mathrm{C} 12, \mathrm{C} 13)$ & 1.475 & $\mathrm{~A}(\mathrm{C} 12, \mathrm{C} 13, \mathrm{O} 25)$ & 121.45 & $\mathrm{D}(\mathrm{C} 9, \mathrm{C} 10, \mathrm{C} 11, \mathrm{~S} 21)$ & 178.10 \\
\hline $\mathrm{R}(\mathrm{C} 12, \mathrm{~N} 26)$ & 1.321 & $\mathrm{~A}(\mathrm{~N} 26, \mathrm{~N} 27, \mathrm{C} 28)$ & 119.70 & $\mathrm{D}(\mathrm{C} 11, \mathrm{C} 12, \mathrm{C} 13, \mathrm{O} 25)$ & $\mathbf{1 7 9 . 9 3}$ \\
\hline $\mathrm{R}(\mathrm{C} 13, \mathrm{O} 25)$ & 1.252 & $\mathrm{~A}(\mathrm{~N} 26, \mathrm{~N} 27, \mathrm{H} 39)$ & 117.77 & $\mathrm{D}(\mathrm{N} 26, \mathrm{C} 12, \mathrm{C} 13, \mathrm{C} 14)$ & -179.42 \\
\hline$R(N 26, N 27)$ & 1.303 & $\mathrm{~A}(\mathrm{C} 28, \mathrm{~N} 27, \mathrm{H} 39)$ & 122.53 & $\mathrm{D}(\mathrm{N} 26, \mathrm{C} 12, \mathrm{C} 13, \mathrm{O} 25)$ & 0.15 \\
\hline $\mathrm{R}(\mathrm{N} 27, \mathrm{C} 28)$ & 1.401 & $\mathrm{~A}(\mathrm{~N} 27, \mathrm{C} 28, \mathrm{C} 29)$ & 121.09 & $\mathrm{D}(\mathrm{C} 11, \mathrm{C} 12, \mathrm{~N} 26, \mathrm{~N} 27)$ & 179.90 \\
\hline $\mathrm{R}(\mathrm{N} 27, \mathrm{H} 39)$ & 1.030 & $\mathrm{~A}(\mathrm{~N} 4, \mathrm{C} 40, \mathrm{C} 41)$ & 117.23 & $\mathrm{D}(\mathrm{C} 13, \mathrm{C} 12, \mathrm{~N} 26, \mathrm{~N} 27)$ & -0.32 \\
\hline $\mathrm{R}(\mathrm{C} 44, \mathrm{C} 45)$ & 1.455 & $\mathrm{~A}(\mathrm{~N} 4, \mathrm{C} 40, \mathrm{C} 49)$ & 123.01 & $\mathrm{D}(\mathrm{C} 12, \mathrm{~N} 26, \mathrm{~N} 27, \mathrm{C} 28)$ & 179.75 \\
\hline $\mathrm{R}(\mathrm{C} 44, \mathrm{~S} 54)$ & 1.850 & $\mathrm{~A}(\mathrm{C} 41, \mathrm{C} 40, \mathrm{C} 49)$ & 119.75 & $\mathrm{D}(\mathrm{C} 12, \mathrm{~N} 26, \mathrm{~N} 27, \mathrm{H} 39)$ & -0.15 \\
\hline $\mathrm{R}(\mathrm{C} 45, \mathrm{C} 46)$ & 1.476 & $\mathrm{~A}(\mathrm{C} 45, \mathrm{C} 44, \mathrm{~S} 54)$ & 120.81 & $\mathrm{D}(\mathrm{N} 26, \mathrm{~N} 27, \mathrm{C} 28, \mathrm{C} 29)$ & -0.30 \\
\hline $\mathrm{R}(\mathrm{C} 45, \mathrm{~N} 59)$ & 1.319 & $\mathrm{~A}(\mathrm{C} 44, \mathrm{C} 45, \mathrm{C} 46)$ & 120.12 & $\mathrm{D}(\mathrm{N} 26, \mathrm{~N} 27, \mathrm{C} 28, \mathrm{C} 33)$ & 179.76 \\
\hline $\mathrm{R}(\mathrm{C} 46, \mathrm{O} 58)$ & 1.253 & $\mathrm{~A}(\mathrm{C} 44, \mathrm{C} 45, \mathrm{~N} 59)$ & 116.82 & $\mathrm{D}(\mathrm{N} 4, \mathrm{C} 40, \mathrm{C} 41, \mathrm{C} 42)$ & -178.74 \\
\hline$R(N 59, N 60)$ & 1.306 & $\mathrm{~A}(\mathrm{C} 46, \mathrm{C} 45, \mathrm{~N} 59)$ & 123.06 & $\mathrm{D}(\mathrm{C} 40, \mathrm{C} 41, \mathrm{C} 42, \mathrm{C} 43)$ & 179.90 \\
\hline $\mathrm{R}(\mathrm{N} 60, \mathrm{C} 61)$ & 1.400 & $\mathrm{~A}(\mathrm{C} 45, \mathrm{C} 46, \mathrm{C} 47)$ & 117.16 & $\mathrm{D}(\mathrm{C} 40, \mathrm{C} 41, \mathrm{C} 42, \mathrm{C} 47)$ & -0.06 \\
\hline $\mathrm{R}(\mathrm{N} 60, \mathrm{H} 72)$ & 1.030 & $\mathrm{~A}(\mathrm{C} 45, \mathrm{C} 46, \mathrm{O} 58)$ & 121.27 & $\mathrm{D}(\mathrm{C} 41, \mathrm{C} 42, \mathrm{C} 47, \mathrm{C} 46)$ & -179.92 \\
\hline $\mathrm{A}(\mathrm{O} 2, \mathrm{C} 1, \mathrm{~N} 3)$ & 119.22 & $\mathrm{~A}(\mathrm{C} 47, \mathrm{C} 46, \mathrm{O} 58)$ & 121.58 & $\mathrm{D}(\mathrm{N} 59, \mathrm{C} 45, \mathrm{C} 46, \mathrm{O} 58)$ & -0.28 \\
\hline $\mathrm{A}(\mathrm{O} 2, \mathrm{C} 1, \mathrm{~N} 4)$ & 124.90 & $\mathrm{~A}(\mathrm{~N} 59, \mathrm{~N} 60, \mathrm{C} 61)$ & 119.48 & $\mathrm{D}(\mathrm{C} 44, \mathrm{C} 45, \mathrm{~N} 59, \mathrm{~N} 60)$ & 179.90 \\
\hline $\mathrm{A}(\mathrm{N} 3, \mathrm{C} 1, \mathrm{~N} 4)$ & 115.86 & $\mathrm{~A}(\mathrm{~N} 59, \mathrm{~N} 60, \mathrm{H} 72)$ & 117.72 & $\mathrm{D}(\mathrm{C} 45, \mathrm{~N} 59, \mathrm{~N} 60, \mathrm{C} 61)$ & -179.67 \\
\hline $\mathrm{A}(\mathrm{C} 1, \mathrm{~N} 3, \mathrm{H} 6)$ & 110.27 & $\mathrm{~A}(\mathrm{C} 61, \mathrm{~N} 60, \mathrm{H} 72)$ & 122.80 & $\mathrm{D}(\mathrm{C} 45, \mathrm{~N} 59, \mathrm{~N} 60, \mathrm{H} 72)$ & 0.06 \\
\hline $\mathrm{A}(\mathrm{C} 1, \mathrm{~N} 3, \mathrm{C} 7)$ & 133.77 & $\mathrm{~A}(\mathrm{~N} 60, \mathrm{C} 61, \mathrm{C} 62)$ & 121.01 & $\mathrm{D}(\mathrm{N} 59, \mathrm{~N} 60, \mathrm{C} 61, \mathrm{C} 62)$ & 0.18 \\
\hline $\mathrm{A}(\mathrm{H} 6, \mathrm{~N} 3, \mathrm{C} 7)$ & 115.93 & $\mathrm{D}(\mathrm{O} 2, \mathrm{C} 1, \mathrm{~N} 3, \mathrm{H} 6)$ & 11.81 & $\mathrm{D}(\mathrm{N} 60, \mathrm{C} 61, \mathrm{C} 62, \mathrm{C} 63)$ & 179.97 \\
\hline $\mathrm{A}(\mathrm{C} 1, \mathrm{~N} 4, \mathrm{H} 5)$ & 116.56 & $\mathrm{D}(\mathrm{O} 2, \mathrm{C} 1, \mathrm{~N} 3, \mathrm{C} 7)$ & -170.64 & $\mathrm{D}(\mathrm{C} 41, \mathrm{C} 42, \mathrm{C} 47, \mathrm{C} 48)$ & 0.00 \\
\hline $\mathrm{A}(\mathrm{C} 1, \mathrm{~N} 4, \mathrm{C} 40)$ & 128.15 & $\mathrm{D}(\mathrm{N} 4, \mathrm{C} 1, \mathrm{~N} 3, \mathrm{H} 6)$ & -166.69 & $\mathrm{D}(\mathrm{C} 44, \mathrm{C} 45, \mathrm{C} 46, \mathrm{O} 58)$ & 179.89 \\
\hline $\mathrm{A}(\mathrm{H} 5, \mathrm{~N} 4, \mathrm{C} 40)$ & 115.18 & $\mathrm{D}(\mathrm{N} 4, \mathrm{C} 1, \mathrm{~N} 3, \mathrm{C} 7)$ & 10.86 & $\mathrm{D}(\mathrm{N} 59, \mathrm{C} 45, \mathrm{C} 46, \mathrm{C} 47)$ & 179.67 \\
\hline
\end{tabular}

Values are mean $\pm S D$ triplicate assays. 
Table 2. The selected geometrical parameters (a.u), bond length $(\AA)$ and binding energy, (kcal/mol) of D1 at B3lyp/6-311++G(d,p) level of theory.

\begin{tabular}{|c|c|c|c|c|c|c|}
\hline & N27H39...O25 & N60H72...O58 & C1O2...H50C49 & S21023...H20C10 & S54056...H53C43 & N4H5...H17C16 \\
\hline HB length $(\AA)$ & 1.764 & 1.766 & 2.211 & 2.334 & 2.345 & 2.135 \\
\hline Density of all electrons & 0.0427 & 0.0428 & 0.0180 & 0.0156 & 0.0159 & 0.0125 \\
\hline Lagrangian kinetic energy G(r) & 0.0379 & 0.0380 & 0.0144 & 0.0133 & 0.0134 & 0.0097 \\
\hline Hamiltonian kinetic energy $\mathrm{K}(\mathrm{r})$ & 0.0015 & 0.0015 & -0.0023 & -0.0020 & -0.0020 & -0.0021 \\
\hline Potential energy density V(r) & -0.0394 & -0.0395 & -0.0121 & -0.0112 & -0.0114 & -0.0076 \\
\hline Energy density E(r) or H(r) & -0.0015 & -0.0015 & 0.0023 & 0.0020 & 0.0020 & 0.0021 \\
\hline Laplacian of electron density & 0.1455 & 0.1458 & 0.0665 & 0.0611 & 0.0618 & 0.0470 \\
\hline $\begin{array}{l}\text { Binding energy of } \mathrm{HB} \\
(\mathrm{BE}=0.5 \mathrm{~V}(\mathrm{r}))[93]\end{array}$ & -12.36 & -12.41 & -3.80 & -3.53 & -3.57 & -2.37 \\
\hline $\begin{array}{l}\text { Binding energy of HB based on } \\
\text { electron density [95] }\end{array}$ & -8.78 & -8.80 & -3.26 & -2.73 & -2.80 & -2.05 \\
\hline
\end{tabular}


Table 3. Selected vibrational analysis at B3LYP/6-311+G(d,p) level of theory for D1 (corresponding FTIR values are also included)

\begin{tabular}{|c|c|c|c|c|}
\hline Freq. & Sc. Freq. & IR int. & FTIR & PED \% ${ }^{a}$ with vibrational assignments ${ }^{\mathrm{b}}$ (mode) \\
\hline 3617 & 3473 & 56.5 & \multirow{4}{*}{3466} & $(-93.2 \%) v(\mathbf{N} 3 \mathbf{H} 6)+(-6.8 \%) \tau(\mathbf{N} 3 \mathbf{C} 7 \mathbf{C} 16 \mathbf{H} 17)$ \\
\hline 3594 & 3450 & 115.7 & & $(+100.0 \%) v(\mathbf{N} 4 \mathbf{H} 5)$ \\
\hline 3269 & 3138 & 33.6 & & $(+91.3 \%) v(\mathbf{N} 60 \mathbf{H} 72)+(+8.7 \%) \tau(\mathbf{N} 59 \mathbf{C} 45 \mathbf{C} 46 \mathbf{O} 58)$ \\
\hline 3263 & 3133 & 31.3 & & $(+74.1 \%) v(\mathbf{N} 27 \mathbf{H} 39+(+15.8 \%) \tau(\mathbf{H} 39 \mathbf{N} 27 \mathbf{C} 28 \mathbf{C} 33)+(-10.2 \%) \gamma(\mathbf{N} 26 \mathbf{N} 27 \mathbf{C} 28 \mathbf{H} 39)$ \\
\hline 3247 & 3117 & 7.8 & \multirow{2}{*}{3090} & $(-89.9 \%) v(\mathbf{C} 49 \mathbf{H} 50)+(-10.1 \%) v(\mathbf{C} 48 \mathbf{H} 51)$ \\
\hline 3150 & 3024 & 7.6 & & 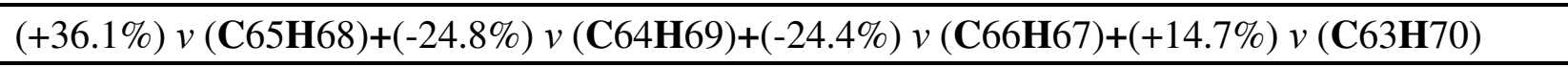 \\
\hline 1742 & 1672 & 668.2 & \multirow{2}{*}{1638} & $(+72.3 \%) v(\mathbf{C} 1 \mathbf{O} 2)+(-10.6 \%) v(\mathbf{C} 1 \mathbf{N} 4)+(-8.6 \%) \delta(\mathbf{C} 1 \mathbf{N} 4 \mathbf{H} 5)+(+8.5 \%) \delta(\mathbf{C} 1 \mathbf{N} 3 \mathbf{H} 6)$ \\
\hline 1648 & 1582 & 230.8 & & $(-100.0 \%) v(\mathbf{C} 13 \mathbf{O} 25)$ \\
\hline 1640 & 1574 & 83.4 & \multirow{4}{*}{1600} & $(-58.3 \%) v(\mathbf{C} 43 \mathbf{C} 44)+(-41.7 \%) v(\mathbf{C} 48 \mathbf{C} 49)$ \\
\hline 1638 & 1573 & 120 & & $(+38.9 \%) v(\mathbf{C} 65 \mathbf{C} 66)+(+36.7 \%) v(\mathbf{C} 62 \mathbf{C} 63)+(+24.7 \%) v(\mathbf{C} 43 \mathbf{C} 44)$ \\
\hline 1637 & 1571 & 239.1 & & $(+64.6 \%) v(\mathbf{C} 10 \mathbf{C} 11)+(+35.4 \%) v(\mathbf{C} 15 \mathbf{C} 16)$ \\
\hline 1624 & 1559 & 34.7 & & $(-27.0 \%) v(\mathbf{C} 61 \mathbf{C} 62)+(-26.6 \%) v(\mathbf{C} 10 \mathbf{C} 11)+(-23.3 \%) v \mathbf{C} 64 \mathbf{C} 65+(+22.5 \%) v \mathbf{C} 63 \mathbf{C} 64$ \\
\hline 1603 & 1539 & 212 & \multirow{2}{*}{1638} & $(-47.2 \%) v(\mathbf{C} 13 \mathbf{O} 25)+(-28.6 \%) v(\mathbf{C} 46 \mathbf{O 5} 8)+(-24.2 \%) v(\mathbf{C} 10 \mathbf{C} 11)$ \\
\hline 1597 & 1533 & 300.2 & & $(-66.5 \%) v(\mathbf{C} 46 \mathbf{O} 58)+(+34.5 \%) v(\mathbf{C} 13 \mathbf{O} 25)$ \\
\hline 1593 & 1529 & 101.3 & \multirow{2}{*}{1600} & $(+66.5 \%) v(\mathbf{C} 43 \mathbf{C} 44)+(33.5 \%) v(\mathbf{C} 40 \mathbf{C} 49)$ \\
\hline 1580 & 1516 & 19.9 & & $(+34.3 \%) v(\mathbf{C} 7 \mathbf{C} 16)+(+24.3 \%) v(\mathbf{C} 10 \mathbf{C} 11)+(-23.0 \%) v(\mathbf{C} 14 \mathbf{C} 15)+(+18.3 \%) v(\mathbf{C} 9 \mathbf{C} 14)$ \\
\hline 1561 & 1499 & 218.9 & \multirow{3}{*}{1490} & $(+100 \%) v(\mathbf{C} 12 \mathbf{N} 26)$ \\
\hline 1558 & 1496 & 526.6 & & $(+33.2 \%) v(\mathbf{C} 45 \mathbf{N} 59)+(+22.5 \%) v(\mathbf{C} 12 \mathbf{N} 26)+(-22.5 \%) v(\mathbf{N} 59 \mathbf{N} 60)+(+21.8 \%) \delta \mathbf{N} 59(\mathbf{N} 60 \mathbf{H} 72)$ \\
\hline 1525 & 1464 & 41.6 & & 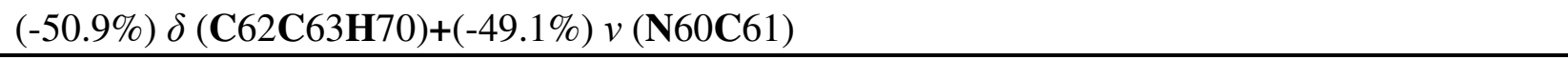 \\
\hline 1441 & 1384 & 129.3 & \multirow{4}{*}{1300} & $(-38.6 \%) v(\mathbf{C} 45 \mathbf{N} 59)+(+33.0 \%) v(\mathbf{C} 41 \mathbf{C} 42)+(+29.0 \%) v(\mathbf{C} 44 \mathbf{C} 45)$ \\
\hline 1426 & 1369 & 526.1 & & $(-100 \%) v(\mathbf{C} 45 \mathbf{N} 59)$ \\
\hline 1414 & 1357 & 365 & & $(-100 \%) v(\mathbf{C} 12 \mathbf{N} 26)$ \\
\hline 1380 & 1325 & 61.4 & & $(-100 \%) v(\mathbf{C} 44 \mathbf{C} 45)$ \\
\hline 1316 & 1263 & 56.9 & \multirow[t]{2}{*}{1250} & $(+100 \%) v(\mathbf{N} 26 \mathbf{N} 27)$ \\
\hline 1294 & 1242 & 232.3 & & $(+100.0 \%) v(\mathbf{N} 4 \mathbf{C} 40)$ \\
\hline
\end{tabular}




\begin{tabular}{|c|c|c|c|c|}
\hline 1265 & 1214 & $\mid 1336.6$ & & $(+56.7 \%) v(\mathbf{C} 1 \mathbf{N} 3)+(-43.3 \%) v(\mathbf{C} 1 \mathbf{N} 4)$ \\
\hline 1254 & 1203 & 804 & & $(+100.0 \%) v(\mathbf{N} 59 \mathbf{N} 60)$ \\
\hline 1196 & 1148 & 213.6 & \multirow{2}{*}{1150} & $(-100.0 \%) v(\mathbf{S} 54 \mathbf{O 5} 5)$ \\
\hline 1193 & 1145 & 245 & & $(+100.0 \%) v(\mathbf{S} 21 \mathbf{O} 23)$ \\
\hline 1187 & 1140 & 80 & \multirow[b]{2}{*}{1120} & $(+100.0 \%) \delta(\mathbf{C} 65 \mathbf{C} 66 \mathbf{H} 67)$ \\
\hline 1186 & 1138 & 443.2 & & $(+100.0 \%) v(\mathbf{C} 28 \mathbf{C} 33)$ \\
\hline 1173 & 1126 & 289.4 & \multirow{2}{*}{1110} & $(-53.4 \%) v(\mathbf{S} 21 \mathbf{O} 24)+(+64.6 \%) v(\mathbf{S} 21 \mathbf{O} 22)$ \\
\hline 1163 & 1117 & 102.3 & & $(+48.3 \%) v(\mathbf{S} 21 \mathbf{O} 23)+(-32.1 \%) v(\mathbf{S} 21 \mathbf{O} 22)+(-19.6 \%) v(\mathbf{S} 21 \mathbf{O} 24)$ \\
\hline 757 & 727 & 59.2 & \multirow{2}{*}{730} & $(+23.3 \%) \tau(\mathbf{C} 28 \mathbf{C} 29 \mathbf{C} 30 \mathbf{C} 31)+(+20.6 \%) \gamma(\mathbf{N} 27 \mathbf{C} 28 \mathbf{C} 29 \mathbf{C} 33)+(+18.4 \%) \gamma(\mathbf{C} 31 \mathbf{C} 32 \mathbf{C} 33 \mathbf{H} 35)+(+14.6 \%) \tau(\mathbf{C} 28 \mathbf{C} 3$ \\
\hline 757 & 727 & 62.2 & & 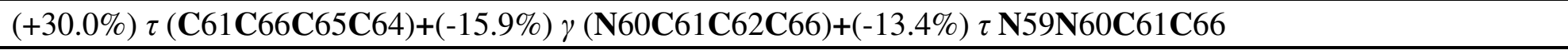 \\
\hline 679 & 652 & 23.6 & \multirow{4}{*}{615} & $(+100.0 \%) \delta(\mathbf{C} 7 \mathbf{C} 8 \mathbf{C} 9)$ \\
\hline 648 & 623 & 22 & & $(+100.0 \%) v(\mathbf{C} 29 \mathbf{C} 30)$ \\
\hline 637 & 611 & 57.2 & & $(+100.0 \%) v(\mathbf{C} 44 \mathbf{C} 45)$ \\
\hline 632 & 607 & 82.8 & & $(+100.0 \%) \delta(\mathbf{C} 31 \mathbf{C} 32 \mathbf{C} 33)$ \\
\hline 628 & 603 & 35.5 & \multirow{3}{*}{597} & $(+100.0 \%) \delta(\mathbf{C} 31 \mathbf{C} 32 \mathbf{C} 33)$ \\
\hline 623 & 598 & 21.9 & & $(+100.0 \%) \gamma(\mathbf{N} 3 \mathbf{C} 7 \mathbf{C} 8 \mathbf{C} 16)$ \\
\hline 622 & 597 & 19.2 & & $(+40.2 \%) \gamma(\mathbf{N} 4 \mathbf{C} 40 \mathbf{C} 41 \mathbf{C} 49)+(-29.9 \%) \tau(\mathbf{C} 43 \mathbf{C} 42 \mathbf{C} 47 \mathbf{C} 48)+(-29.9 \%) \gamma(\mathbf{C} 43 \mathbf{C} 44 \mathbf{C} 45 \mathbf{S} 54)$ \\
\hline 592 & 568 & 20.4 & \multirow{3}{*}{560} & $(+100.0 \%) v(\mathbf{C} 46 \mathbf{C} 47)$ \\
\hline 588 & 564 & 69.3 & & $(-64.2 \%) \delta(\mathbf{C} 8 \mathbf{C} 9 \mathbf{C} 14)+(+35.8 \%) \delta(\mathbf{C} 13 \mathbf{C} 14 \mathbf{C} 15)$ \\
\hline 578 & 555 & 79.3 & & $(+100.0 \%) \delta(\mathbf{C} 40 \mathbf{C} 41 \mathbf{C} 42)$ \\
\hline 557 & 535 & 27.2 & \multirow[b]{2}{*}{520} & $(+100.0 \%) v(\mathbf{N} 4 \mathbf{C} 40)$ \\
\hline 545 & 523 & 21.8 & & $(-100.0 \%) v(\mathbf{C} 13 \mathbf{C} 14)$ \\
\hline 511 & 490 & 36.6 & \multirow{3}{*}{$\begin{array}{l}480 \\
450 \\
\end{array}$} & $(-100.0 \%) \delta(\mathbf{C} 45 \mathbf{C} 46 \mathbf{C} 47)$ \\
\hline 508 & 488 & 1.4 & & $(-51.0 \%) \delta(\mathbf{C} 29 \mathbf{C} 28 \mathbf{C} 33)+(-49.0 \%) v(\mathbf{C} 12 \mathbf{C} 13)$ \\
\hline 477 & 458 & 4 & & $(-41.2 \%) \delta(\mathbf{C} 45 \mathbf{C} 46 \mathbf{O} 58)+(-29.9 \%) v(\mathbf{C} 45 \mathbf{C} 46)+(-28.9 \%) \delta(\mathbf{C} 46 \mathbf{C} 45 \mathbf{N} 59)$ \\
\hline 428 & 411 & 17.2 & \multirow{3}{*}{400} & $(+100.0 \%) \delta(\mathbf{C} 13 \mathbf{C} 14 \mathbf{C} 15)$ \\
\hline 425 & 408 & 11.7 & & $(-100.0 \%) \tau(\mathbf{C} 43 \mathbf{C} 42 \mathbf{C} 47 \mathbf{C} 48)$ \\
\hline 419 & 402 & 38 & & $(+100.0 \%) \delta(\mathbf{C} 13 \mathbf{C} 14 \mathbf{C} 15)$ \\
\hline
\end{tabular}


${ }^{\text {a }}$ PED $<10 \%$ are not included in assignments.

${ }^{\mathrm{b}}$ Symbols: $v=$ Stretching, $\delta=$ Bending, $\tau$ and $\gamma=$ torsional motions, $+=$ out of phase, $-=$ in phase

Expressions represent: (direction of phase, percentage contribution in normal mode\%) vibrational normal mode (Atom composition mode motions) 
Table 4. Natural charge of selected atoms of DO-26 dye1 (D1) at B31yp/6-311++G(d,p) level of theory.

\begin{tabular}{|l|r|l|r|l|r|}
\hline Atoms & Charge & Atoms & Charge & Atoms & Charge \\
\hline C1 & 0.817 & O25 & -0.666 & $\mathbf{C 4 9}$ & -0.261 \\
\hline O2 & -0.661 & $\mathbf{N 2 6}$ & -0.153 & $\mathbf{H 5 0}$ & 0.241 \\
\hline N3 & -0.63 & $\mathbf{N 2 7}$ & -0.272 & $\mathbf{H 5 1}$ & 0.223 \\
\hline N4 & -0.623 & $\mathbf{C 2 8}$ & 0.135 & $\mathbf{H 5 2}$ & 0.202 \\
\hline H5 & 0.403 & $\mathbf{C 2 9}$ & -0.209 & $\mathbf{H 5 3}$ & 0.241 \\
\hline H6 & 0.401 & $\mathbf{C 3 0}$ & -0.189 & $\mathbf{S 5 4}$ & 2.298 \\
\hline C7 & 0.161 & $\mathbf{C 3 1}$ & -0.234 & $\mathbf{O 5 5}$ & -0.984 \\
\hline C8 & -0.24 & $\mathbf{C 3 2}$ & -0.204 & $\mathbf{O 5 6}$ & -0.999 \\
\hline C9 & 0.113 & $\mathbf{C 3 3}$ & -0.231 & $\mathbf{O 5 7}$ & -0.985 \\
\hline C10 & -0.262 & $\mathbf{H 3 4}$ & 0.205 & $\mathbf{O 5 8}$ & -0.671 \\
\hline C11 & -0.207 & $\mathbf{H 3 5}$ & 0.195 & $\mathbf{N 5 9}$ & -0.187 \\
\hline C12 & 0.03 & $\mathbf{H 3 6}$ & 0.194 & $\mathbf{N 6 0}$ & -0.282 \\
\hline C13 & 0.484 & $\mathbf{H 3 7}$ & 0.202 & $\mathbf{C 6 1}$ & 0.137 \\
\hline C14 & -0.197 & $\mathbf{H 3 8}$ & 0.267 & $\mathbf{C 6 2}$ & -0.21 \\
\hline C15 & -0.115 & $\mathbf{H 3 9}$ & 0.417 & $\mathbf{C 6 3}$ & -0.189 \\
\hline C16 & -0.287 & $\mathbf{C 4 0}$ & 0.181 & $\mathbf{C 6 4}$ & -0.238 \\
\hline H17 & 0.213 & $\mathbf{C 4 1}$ & -0.214 & $\mathbf{C 6 5}$ & -0.206 \\
\hline H18 & 0.229 & $\mathbf{C 4 2}$ & -0.014 & $\mathbf{C 6 6}$ & -0.235 \\
\hline H19 & 0.201 & $\mathbf{C 4 3}$ & -0.222 & $\mathbf{H 6 7}$ & 0.202 \\
\hline H20 & 0.24 & $\mathbf{C 4 4}$ & -0.256 & $\mathbf{H 6 8}$ & 0.193 \\
\hline S21 & 2.299 & $\mathbf{C 4 5}$ & 0.16 & $\mathbf{H 6 9}$ & 0.193 \\
\hline O22 & -0.983 & $\mathbf{C 4 6}$ & 0.454 & $\mathbf{H 7 0}$ & 0.201 \\
\hline O23 & -1.001 & $\mathbf{C 4 7}$ & -0.166 & $\mathbf{H 7 1}$ & 0.268 \\
\hline O24 & -0.981 & $\mathbf{C 4 8}$ & -0.12 & $\mathbf{H 7 2}$ & 0.415 \\
\hline Values & Hean & SD & \\
\hline
\end{tabular}

Values are mean \pm SD triplicate assays.

Table 5. Energetic parameters and reactivity indices of synthesized DO-26 dye1 (D1) at B3lyp/6$311++G(d, p)$ level of theory.

\begin{tabular}{|c|c|c|c|c|c|c|c|}
\hline Parameters & ET,au & EHOMO,au & ELUMO,au & Eg,eV & I,eV & $\mathrm{A}, \mathrm{eV}$ & $\mu, \mathrm{D}$ \\
\hline D1 & -3073.35409 & -0.06336 & 0.02557 & 2.42 & 1.72 & -0.70 & 10.98 \\
\hline Parameters & $\mathrm{X}, \mathrm{eV}$ & $\eta, \mathrm{eV}$ & S,eV & $\mathbf{V}, \mathbf{e V}$ & $\omega, \mathrm{eV}$ & $\mathrm{N}, \mathrm{eV}$ & \\
\hline D1 & 0.51 & 1.21 & 0.41 & -0.51 & 0.11 & 2.49 & \\
\hline
\end{tabular}

Values are mean $\pm S D$ triplicate assays. 
Table 6. Values of the Fukui functions and Dual descriptor of DO-26 dye (D1) at B3lyp/6-311++G(d,p) level of calculation.

\begin{tabular}{|c|c|c|c|c|c|c|c|}
\hline Atom & $f(-)$ & $\mathbf{f}(+)$ & $\Delta \mathbf{f}$ & Atom & $f(-)$ & $f(+)$ & $\Delta \mathbf{f}$ \\
\hline $\mathrm{C} 1$ & 0.000 & 0.007 & 0.007 & $\mathrm{C28}$ & 0.000 & 0.015 & 0.015 \\
\hline $\mathbf{O 2}$ & 0.000 & 0.009 & 0.009 & C29 & 0.000 & 0.034 & 0.034 \\
\hline N3 & 0.000 & 0.009 & 0.009 & C30 & 0.000 & 0.003 & 0.003 \\
\hline $\mathrm{N4}$ & 0.000 & 0.000 & 0.000 & C31 & 0.000 & 0.040 & 0.040 \\
\hline C7 & 0.000 & 0.053 & 0.053 & C32 & 0.000 & 0.007 & 0.007 \\
\hline $\mathrm{C8}$ & 0.000 & 0.004 & 0.004 & C33 & 0.000 & 0.023 & 0.023 \\
\hline C9 & 0.000 & 0.051 & 0.051 & H39 & 0.000 & 0.001 & 0.001 \\
\hline $\mathrm{C10}$ & 0.000 & 0.018 & 0.018 & $\mathbf{C 4 0}$ & 0.000 & 0.008 & 0.007 \\
\hline C11 & 0.000 & 0.037 & 0.037 & C41 & 0.000 & 0.000 & 0.000 \\
\hline $\mathrm{C} 12$ & 0.000 & 0.021 & 0.021 & C47 & 0.000 & 0.004 & 0.004 \\
\hline $\mathrm{C} 13$ & 0.000 & 0.131 & 0.131 & $\mathrm{C48}$ & 0.000 & 0.003 & 0.003 \\
\hline C14 & 0.000 & 0.036 & 0.036 & 055 & $\mathbf{0 . 3 3 3}$ & 0.000 & -0.333 \\
\hline C15 & 0.000 & 0.044 & 0.044 & 056 & 0.324 & 0.000 & -0.324 \\
\hline C16 & 0.000 & 0.013 & 0.013 & 057 & 0.334 & 0.000 & -0.334 \\
\hline S21 & 0.000 & 0.000 & 0.000 & 058 & 0.001 & 0.007 & 0.006 \\
\hline $\mathbf{O 2 2}$ & 0.000 & 0.002 & 0.002 & N59 & 0.001 & 0.012 & 0.011 \\
\hline $\mathbf{O 2 3}$ & 0.000 & 0.000 & 0.000 & N60 & 0.000 & 0.005 & 0.005 \\
\hline 024 & 0.000 & 0.002 & 0.002 & C61 & -0.001 & 0.001 & 0.002 \\
\hline 025 & 0.000 & 0.100 & 0.100 & C62 & 0.003 & 0.002 & -0.001 \\
\hline N26 & 0.000 & 0.200 & 0.200 & C63 & -0.001 & 0.000 & 0.001 \\
\hline $\mathbf{N} 27$ & 0.000 & 0.075 & 0.075 & & & & \\
\hline
\end{tabular}

Values are mean $\pm S D$ triplicate assays 
Table 7. Values of the Condensed local Softnesses (Hartree*e), relative electrophilicity/nucleophilicity (dimensionless) and the Condensed local electrophilicity (ElectroP)/nucleophilicity (NucleoP) index (e*V) of DO-26 dye (D1) at B3lyp/6-311++G(d,p) level of calculation.

\begin{tabular}{|c|c|c|c|c|c|c|c|c|}
\hline Atoms & $\mathbf{s}^{-}$ & $\mathbf{s}^{+}$ & Atoms & $\mathbf{s}^{+} / \mathbf{s}^{-}$ & $\mathbf{s}^{-} / \mathbf{s}^{+}$ & Atoms & ElectroP & NucleoP \\
\hline $\mathrm{C} 1$ & -0.076 & -0.027 & $\mathrm{C} 1$ & 0.36 & 2.78 & $\mathrm{C} 1$ & 0.000 & -0.094 \\
\hline $\mathrm{O} 2$ & -0.144 & -0.075 & $\mathrm{O} 2$ & 0.52 & 1.92 & $\mathrm{O} 2$ & -0.001 & -0.178 \\
\hline $\mathrm{N} 3$ & -0.039 & -0.026 & N3 & 0.67 & 1.49 & N3 & 0.000 & -0.048 \\
\hline $\mathrm{N} 4$ & -0.020 & -0.015 & N4 & 0.73 & 1.36 & $\mathrm{~N} 4$ & 0.000 & -0.024 \\
\hline $\mathrm{C} 7$ & -0.125 & -0.032 & $\mathrm{C} 7$ & 0.25 & 3.95 & $\mathrm{C} 7$ & 0.000 & -0.154 \\
\hline $\mathrm{C} 8$ & -0.070 & -0.059 & $\mathrm{C} 8$ & 0.84 & 1.19 & $\mathrm{C} 8$ & 0.000 & -0.086 \\
\hline C9 & -0.094 & -0.010 & $\mathrm{C} 9$ & 0.11 & 9.23 & C9 & 0.000 & -0.117 \\
\hline $\mathrm{C} 10$ & -0.087 & -0.114 & $\mathrm{C} 10$ & 1.30 & 0.77 & $\mathrm{C} 10$ & -0.001 & -0.108 \\
\hline $\mathrm{C} 11$ & -0.053 & -0.014 & $\mathrm{C} 11$ & 0.27 & 3.73 & $\mathrm{C} 11$ & 0.000 & -0.066 \\
\hline C12 & -0.071 & -0.036 & $\mathrm{C} 12$ & 0.51 & 1.97 & $\mathrm{C} 12$ & 0.000 & -0.088 \\
\hline C13 & -0.203 & -0.029 & $\mathrm{C} 13$ & 0.14 & 6.94 & $\mathrm{C} 13$ & 0.000 & -0.250 \\
\hline C14 & -0.062 & -0.027 & $\mathrm{C} 14$ & 0.43 & 2.34 & $\mathrm{C} 14$ & 0.000 & -0.077 \\
\hline $\mathrm{C} 15$ & -0.091 & -0.039 & C15 & 0.42 & 2.36 & $\mathrm{C} 15$ & 0.000 & -0.113 \\
\hline $\mathrm{C} 16$ & -0.076 & -0.052 & $\mathrm{C} 16$ & 0.68 & 1.46 & $\mathrm{C} 16$ & 0.000 & -0.094 \\
\hline S21 & -0.046 & -0.189 & $\mathrm{~S} 21$ & 4.08 & 0.25 & $\mathrm{~S} 21$ & -0.001 & -0.057 \\
\hline $\mathrm{O} 22$ & -0.073 & -0.418 & $\mathrm{O} 22$ & 5.69 & 0.18 & $\mathrm{O} 22$ & -0.003 & -0.091 \\
\hline $\mathrm{O} 23$ & -0.099 & -0.337 & $\mathrm{O} 23$ & 3.40 & 0.29 & $\mathrm{O} 23$ & -0.002 & -0.123 \\
\hline $\mathrm{O} 24$ & -0.070 & -0.411 & $\mathrm{O} 24$ & 5.84 & 0.17 & $\mathrm{O} 24$ & -0.003 & -0.087 \\
\hline $\mathrm{O} 25$ & -0.252 & -0.089 & $\mathrm{O} 25$ & 0.35 & 2.83 & $\mathrm{O} 25$ & -0.001 & -0.311 \\
\hline $\mathrm{N} 26$ & -0.294 & -0.002 & N26 & 0.01 & 176.82 & N26 & 0.000 & -0.364 \\
\hline $\mathrm{N} 27$ & -0.145 & -0.090 & $\mathrm{~N} 27$ & 0.62 & 1.60 & $\mathrm{~N} 27$ & -0.001 & -0.179 \\
\hline $\mathrm{C} 28$ & -0.021 & 0.000 & $\mathrm{C} 28$ & -0.01 & -101.57 & $\mathrm{C} 28$ & 0.000 & -0.026 \\
\hline $\mathrm{C} 29$ & -0.080 & -0.018 & $\mathrm{C} 29$ & 0.22 & 4.52 & $\mathrm{C} 29$ & 0.000 & -0.099 \\
\hline $\mathrm{C} 30$ & -0.089 & -0.046 & $\mathrm{C} 30$ & 0.51 & 1.95 & C30 & 0.000 & -0.110 \\
\hline C31 & -0.173 & -0.103 & C31 & 0.60 & 1.67 & C31 & -0.001 & -0.214 \\
\hline C32 & -0.097 & -0.063 & $\mathrm{C} 32$ & 0.65 & 1.55 & $\mathrm{C} 32$ & 0.000 & -0.119 \\
\hline $\mathrm{C} 33$ & -0.078 & -0.052 & $\mathrm{C} 33$ & 0.66 & 1.52 & C33 & 0.000 & -0.097 \\
\hline $\mathrm{C} 40$ & -0.083 & -0.052 & $\mathrm{C} 40$ & 0.62 & 1.61 & $\mathrm{C} 40$ & 0.000 & -0.103 \\
\hline $\mathrm{C} 41$ & -0.040 & -0.074 & $\mathrm{C} 41$ & 1.85 & 0.54 & $\mathrm{C} 41$ & -0.001 & -0.049 \\
\hline $\mathrm{C} 42$ & -0.072 & -0.007 & $\mathrm{C} 42$ & 0.10 & 10.25 & $\mathrm{C} 42$ & 0.000 & -0.088 \\
\hline $\mathrm{C} 47$ & -0.054 & -0.034 & $\mathrm{C} 47$ & 0.63 & 1.59 & $\mathrm{C} 47$ & 0.000 & -0.067 \\
\hline $\mathrm{C} 48$ & -0.089 & -0.074 & $\mathrm{C} 48$ & 0.83 & 1.21 & $\mathrm{C} 48$ & -0.001 & -0.110 \\
\hline $\mathrm{C} 49$ & -0.071 & -0.106 & $\mathrm{C} 49$ & 1.50 & 0.67 & $\mathrm{C} 49$ & -0.001 & -0.087 \\
\hline S54 & -0.037 & -0.195 & S54 & 5.21 & 0.19 & S54 & -0.001 & -0.046 \\
\hline $\mathrm{O} 55$ & -0.062 & -0.442 & O55 & 7.09 & 0.14 & O55 & -0.003 & -0.077 \\
\hline O56 & -0.068 & -0.324 & O56 & 4.75 & 0.21 & O56 & -0.002 & -0.084 \\
\hline $\mathrm{O} 57$ & -0.065 & -0.442 & O57 & 6.76 & 0.15 & O57 & -0.003 & -0.081 \\
\hline $\mathrm{O} 58$ & -0.218 & -0.138 & O58 & 0.63 & 1.59 & O58 & -0.001 & -0.270 \\
\hline N59 & -0.243 & -0.015 & N59 & 0.06 & 15.82 & N59 & 0.000 & -0.300 \\
\hline $\mathrm{N} 60$ & -0.118 & -0.128 & N60 & 1.08 & 0.92 & N60 & -0.001 & -0.146 \\
\hline C61 & -0.019 & -0.006 & C61 & 0.30 & 3.33 & C61 & 0.000 & -0.023 \\
\hline C62 & -0.065 & -0.030 & C62 & 0.46 & 2.20 & C62 & 0.000 & -0.080 \\
\hline C63 & -0.074 & -0.056 & C63 & 0.75 & 1.33 & C63 & 0.000 & -0.092 \\
\hline
\end{tabular}


Table 8: Absorption maximum wavelengths $\left(\lambda_{\max }\right)$, electronic excitation energies, and oscillator strengths of D1 in water.

\begin{tabular}{|c|c|c|c|c|c|c|c|}
\hline & \multicolumn{2}{|r|}{$\lambda_{\max }(\mathbf{n m})$} & \multirow{2}{*}{$\frac{\varepsilon\left(\mathrm{mol}^{-1} \cdot \mathrm{cm}^{-1} \cdot \mathrm{L}\right)}{\mathrm{Exp} .}$} & \multirow{2}{*}{$f$} & \multicolumn{2}{|c|}{$\Delta E(\mathrm{eV})$} & \multirow{2}{*}{$\begin{array}{c}\text { Transition } \\
\text { assignment }\end{array}$} \\
\hline & Exp. & TD-DFT & & & Exp. & TD-DFT & \\
\hline $\mathbf{S}_{\mathbf{0}} \rightarrow \mathbf{S}_{\mathbf{1}}$ & 511 & $475(\mathrm{H} \rightarrow \mathrm{L}(0.5403))$ & 13,395 & 1.19 & 2.43 & 2.61 & $\pi \rightarrow \pi^{*}$ \\
\hline $\mathbf{S}_{\mathbf{0}} \rightarrow \mathbf{S}_{2}$ & 491 & $466(\mathrm{H}-1 \rightarrow \mathrm{L}(0.584))$ & 14,514 & 0.25 & 2.53 & 2.66 & $\pi \rightarrow \pi^{*}$ \\
\hline $\mathbf{S}_{\mathbf{0}} \rightarrow \mathbf{S}_{\mathbf{3}}$ & 416 & $412(\mathrm{H}-2 \rightarrow \mathrm{L}(0.629))$ & 6,777 & 0.44 & 2.98 & 3.00 & $\pi \rightarrow \pi^{*}$ \\
\hline $\mathbf{S}_{\mathbf{0}} \rightarrow \mathbf{S}_{4}$ & 321 & $319(\mathrm{H}-1 \rightarrow \mathrm{L}+2(0.492))$ & 5,440 & 0.21 & 3.86 & 3.88 & $\pi \rightarrow \pi^{*}$ \\
\hline $\mathbf{S}_{\mathbf{0}} \rightarrow \mathbf{S}_{5}$ & 302 & $303(\mathrm{H} \rightarrow \mathrm{L}+2(0.616))$ & 8,313 & 0.03 & 4.11 & 4.1 & $\pi \rightarrow \pi^{*}$ \\
\hline $\mathbf{S}_{\mathbf{0}} \rightarrow \mathbf{S}_{\mathbf{6}}$ & 272 & $267(\mathrm{H}-12 \rightarrow \mathrm{L}+1(0.239))$ & 7,077 & 0.02 & 4.54 & 4.64 & $\pi \rightarrow \pi^{*}$ \\
\hline
\end{tabular}

Table 9. Percent contributions of molecular fragments to occupied and unoccupied natural transition orbitals in the electronic transitions between the ground state $\left(S_{0}\right)$ and six low-lying singlet excited states $\left(S_{n}\right)$ of D1 obtained at the PCM-B3LYP (Water) /6-311++G(d,p) level of approximation using Hirshfeld population analysis.

\begin{tabular}{|c|l|r|r|r|r|r|r|r|}
\hline & & Urea Center & Napth_R & AzoPh_R & Napth_L & AzoPh_L & Right-arm & Left-arm \\
\hline \multirow{3}{*}{$\mathbf{S}_{\mathbf{0}} \rightarrow \mathbf{S}_{\mathbf{1}}$} & Occ.NTO & 2.61 & 20.08 & 15.06 & 35.24 & 26.63 & 35.15 & 61.87 \\
\cline { 2 - 9 } & Virt.NTO & 3.68 & 29.90 & 21.66 & 25.52 & 18.82 & 51.56 & 44.33 \\
\hline \multirow{3}{*}{$\mathbf{S}_{\mathbf{0}} \rightarrow \mathbf{S}_{\mathbf{2}}$} & Occ.NTO & 0.69 & 35.88 & 22.17 & 24.56 & 16.10 & 58.05 & 40.66 \\
\cline { 2 - 10 } & Virt.NTO & 3.33 & 42.47 & 31.90 & 12.58 & 9.10 & 74.37 & 21.68 \\
\hline \multirow{3}{*}{$\mathbf{S}_{\mathbf{0}} \rightarrow \mathbf{S}_{\mathbf{3}}$} & Occ.NTO & 21.04 & 34.41 & 1.50 & 41.02 & 1.96 & 35.91 & 42.97 \\
\cline { 2 - 10 } & Virt.NTO & 3.69 & 29.82 & 22.12 & 24.88 & 19.04 & 51.95 & 43.92 \\
\hline \multirow{2}{*}{$\mathbf{S}_{\mathbf{0}} \rightarrow \mathbf{S}_{\mathbf{4}}$} & Occ.NTO & 1.22 & 46.73 & 49.27 & 0.89 & 0.56 & 96.00 & 1.44 \\
\cline { 2 - 10 } & Virt.NTO & 3.38 & 93.73 & 0.94 & 1.60 & 0.25 & 94.66 & 1.85 \\
\hline \multirow{3}{*}{$\mathbf{S}_{\mathbf{0}} \rightarrow \mathbf{S}_{\mathbf{5}}$} & Occ.NTO & 2.33 & 1.04 & 0.01 & 55.37 & 41.25 & 1.05 & 96.62 \\
\cline { 2 - 10 } & Virt.NTO & 3.53 & 89.14 & 0.96 & 6.17 & 0.10 & 90.09 & 6.27 \\
\hline \multirow{2}{*}{$\mathbf{S}_{\mathbf{0}} \rightarrow \mathbf{S}_{\mathbf{6}}$} & Occ.NTO & 46.25 & 3.61 & 1.34 & 31.65 & 17.14 & 4.95 & 48.79 \\
\cline { 2 - 10 } & Virt.NTO & 5.27 & 12.39 & 7.42 & 44.02 & 30.75 & 19.81 & 74.77 \\
\hline
\end{tabular}

Table 10. Charge transfer $(\mathrm{CT})$ length $(\Delta \mathrm{r})$ and variation in dipole moment $\left(\Delta \mu_{\mathrm{CT}}\right)$ indices of the six electronic excitations for the studied D1 obtained at the PCM-B3LYP(Water)/6-311++G(d,p) level of approximation.

\begin{tabular}{l|cccccc} 
& $\mathbf{S}_{\mathbf{0}} \rightarrow \mathbf{S}_{\mathbf{1}}$ & $\mathbf{S}_{\mathbf{0}} \rightarrow \mathbf{S}_{\mathbf{2}}$ & $\mathbf{S}_{\mathbf{0}} \rightarrow \mathbf{S}_{\mathbf{3}}$ & $\mathbf{S}_{\mathbf{0}} \rightarrow \mathbf{S}_{\mathbf{4}}$ & $\mathbf{S}_{\mathbf{0}} \rightarrow \mathbf{S}_{\mathbf{5}}$ & $\mathbf{S}_{\mathbf{0}} \rightarrow \mathbf{S}_{\mathbf{6}}$ \\
\hline $\boldsymbol{\Delta} \boldsymbol{r}(\mathbf{\mathbf { A }})$ & 7.61 & 5.36 & 4.06 & 3.75 & 9.22 & 4.70 \\
$\Delta \boldsymbol{\mu}_{\text {CT }}$ (a.u.) & 3.34 & 2.12 & 2.94 & 7.10 & 7.10 & 2.17 \\
\hline
\end{tabular}


Figures

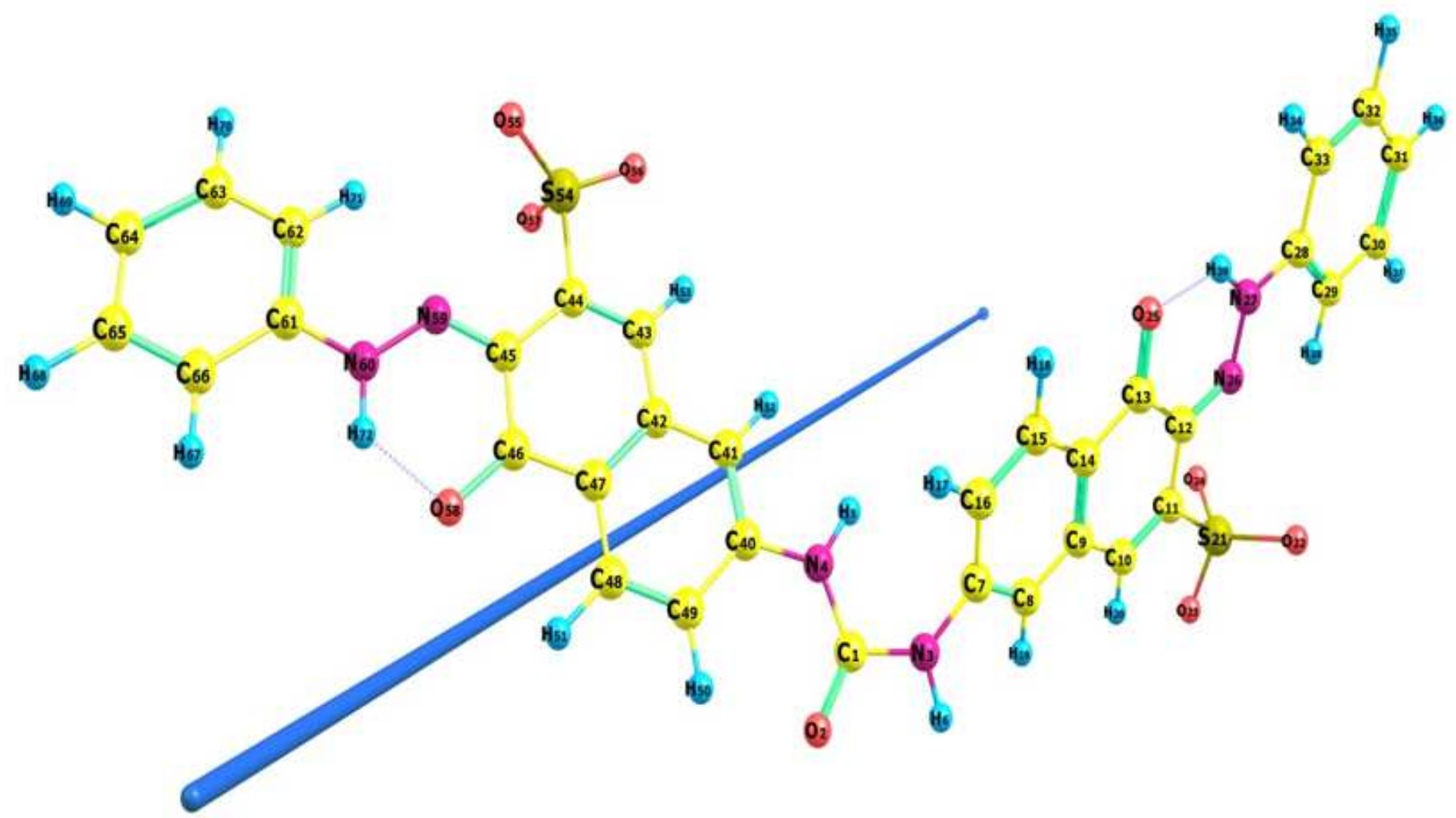

DO-26 dye (D1)

\section{Figure 1}

The optimized geometry of DO-26 dye (D1) compounds using B3LYP/6-311++G(d,p) level of theory, the numbering system and vector of dipole moment. 


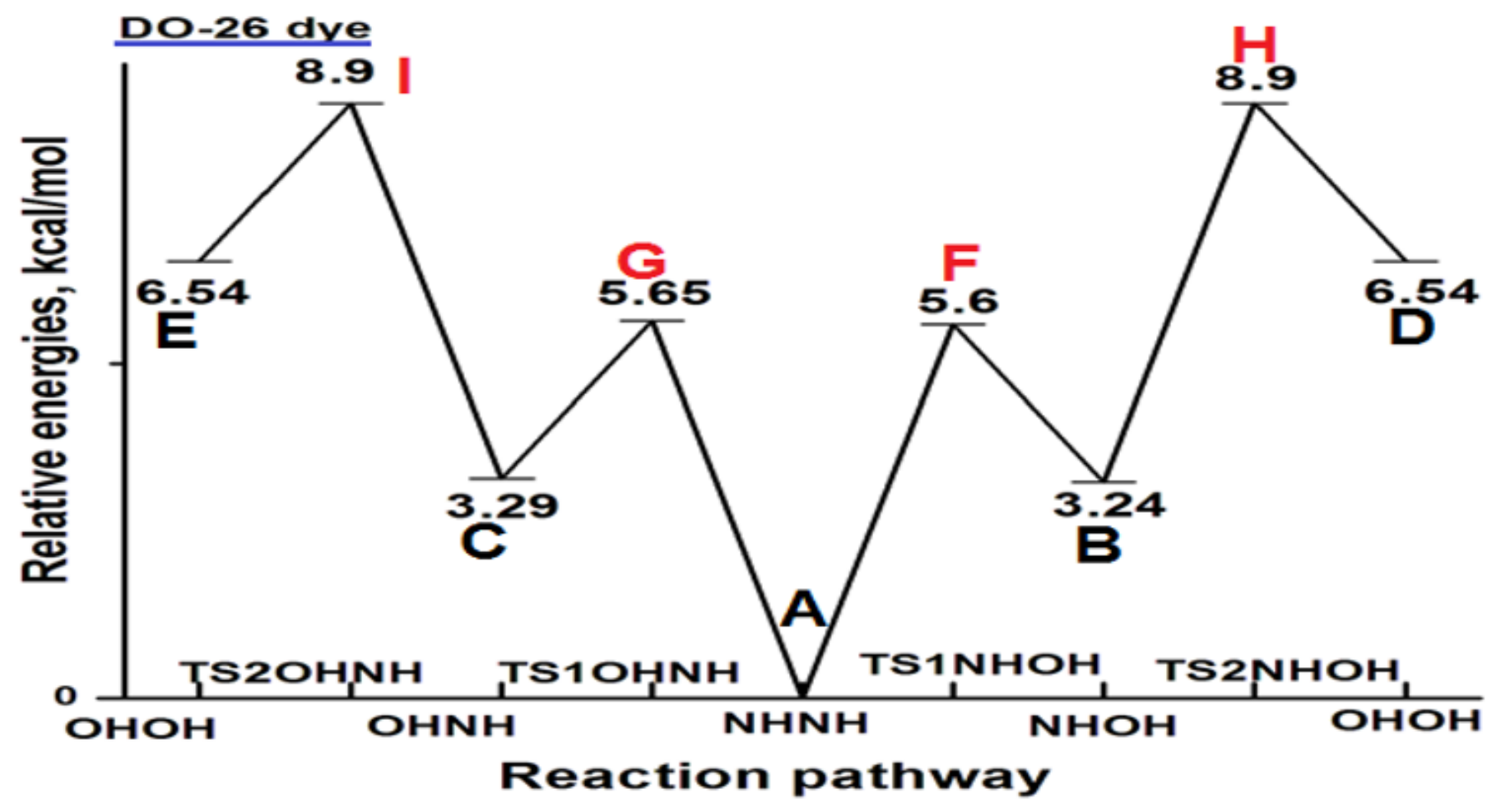

Figure 2

Using the B3LYP/ 6-311++G(d,p) of the DFT theory; the calculated surface relative potential energy values are given for the different tautomeric forms transformations of DO-26 dye (D1). 


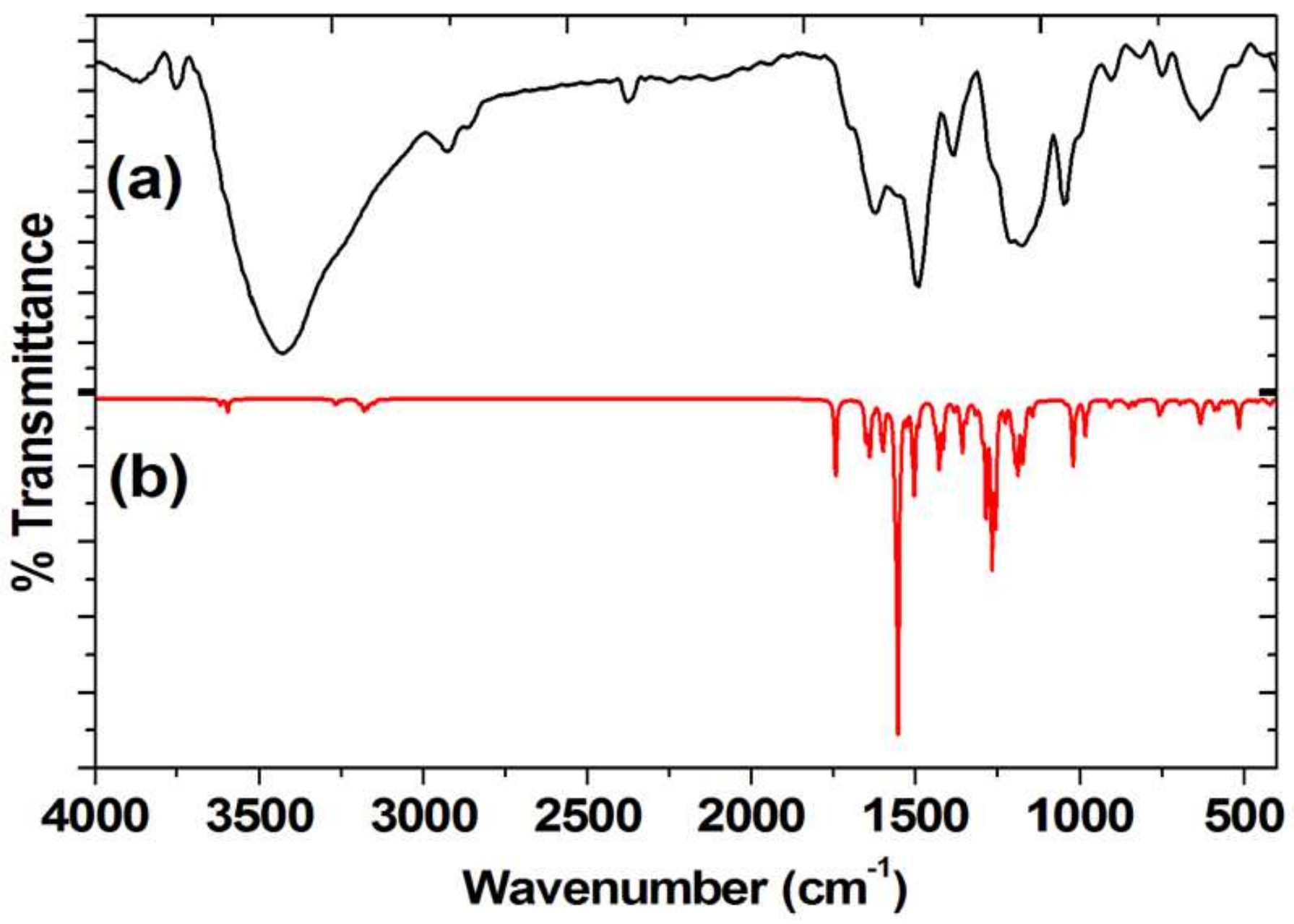

Figure 3

FT-IR spectra of the D0-26 dye (D1) in the region 400-4000 cm-1: (a) Experimental spectra (b) simulated spectra. 


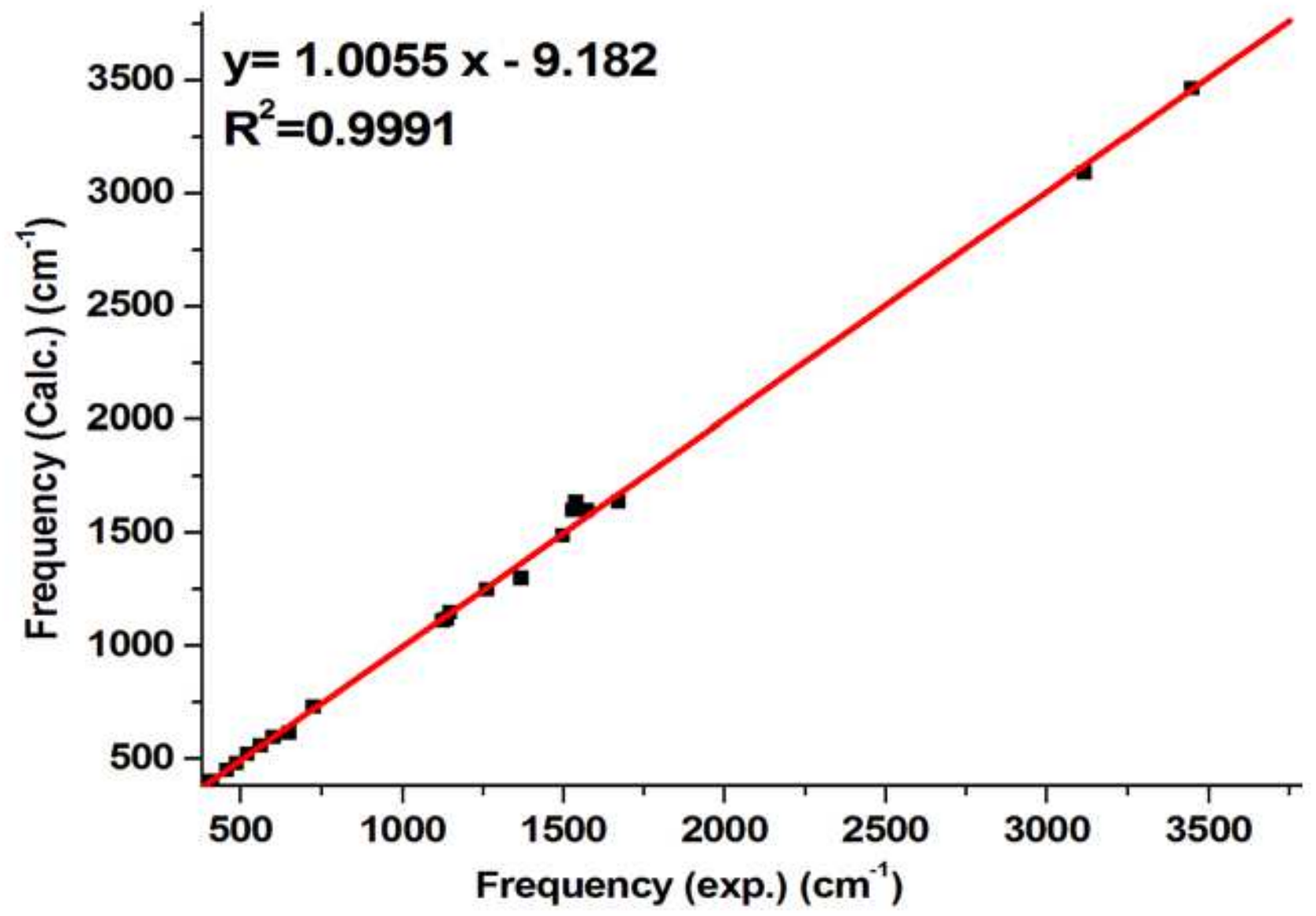

Figure 4

Correlation between experimental FT-IR and simulated IR spectra in the region $4000-400 \mathrm{~cm}-1$ of the DO26 dye (D1).

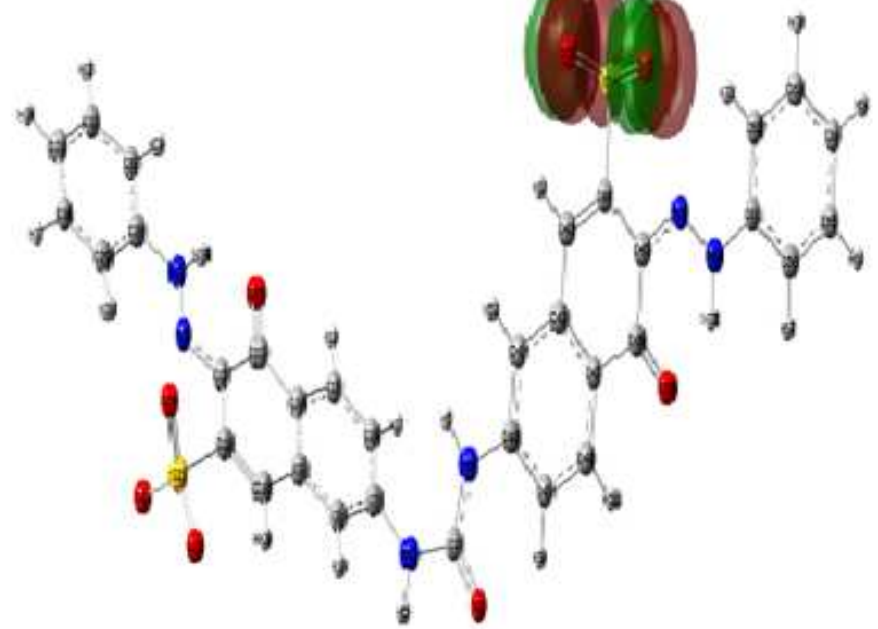

DO-26 dye (HOMO)

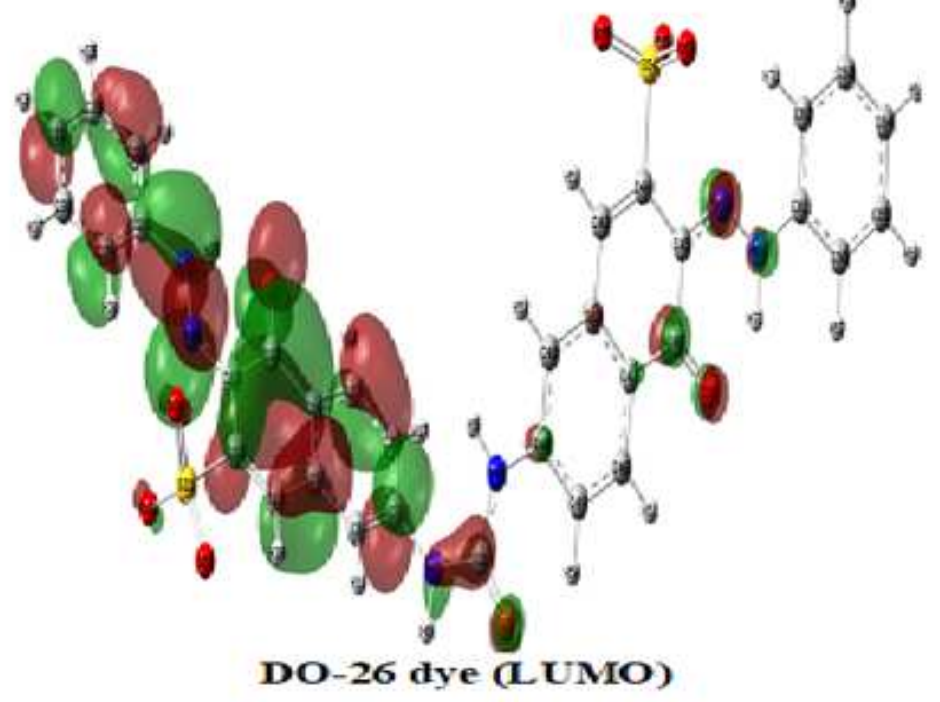

DO-26 dye (LUMO)

Figure 5 


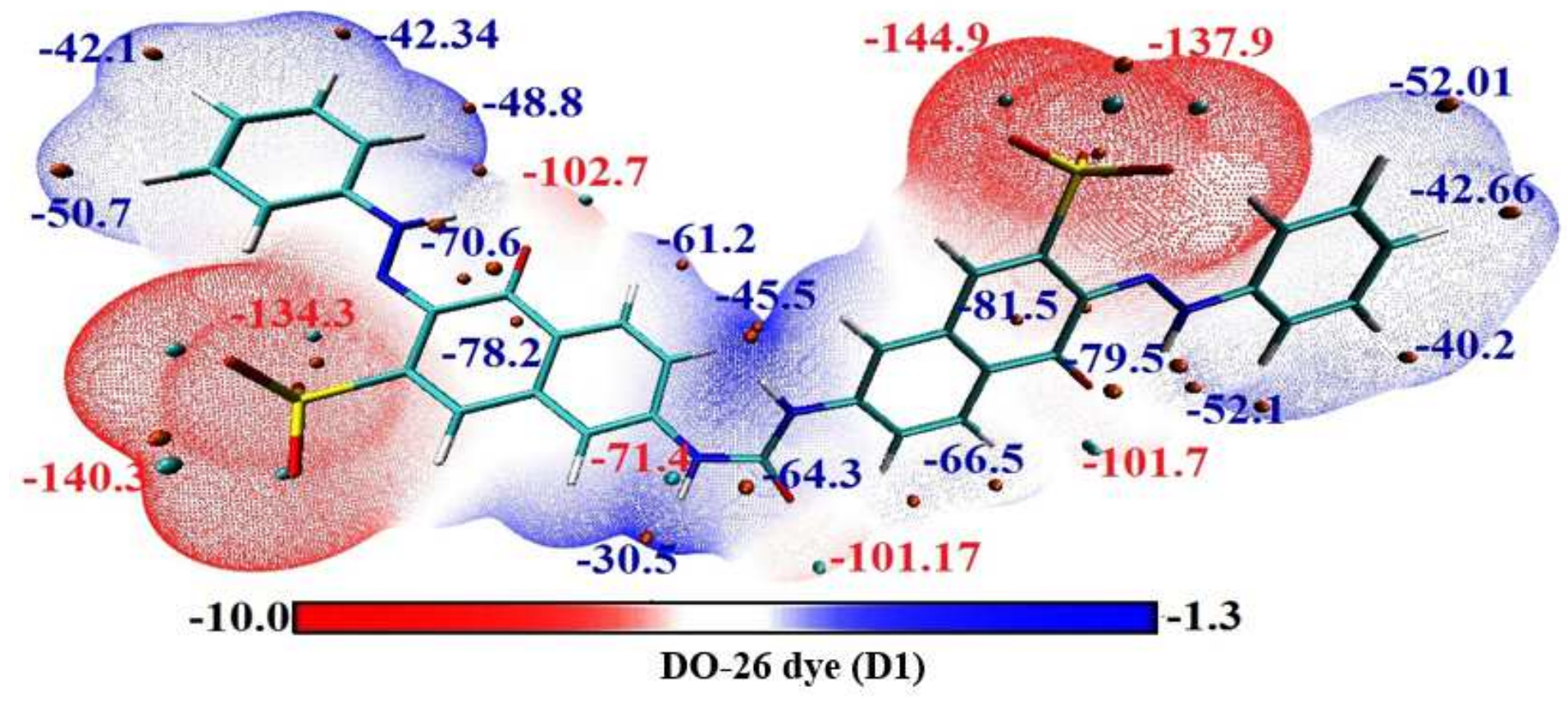

Figure 6

ESP-mapped surfaces of the synthesized DO-26 dye compound (D1)

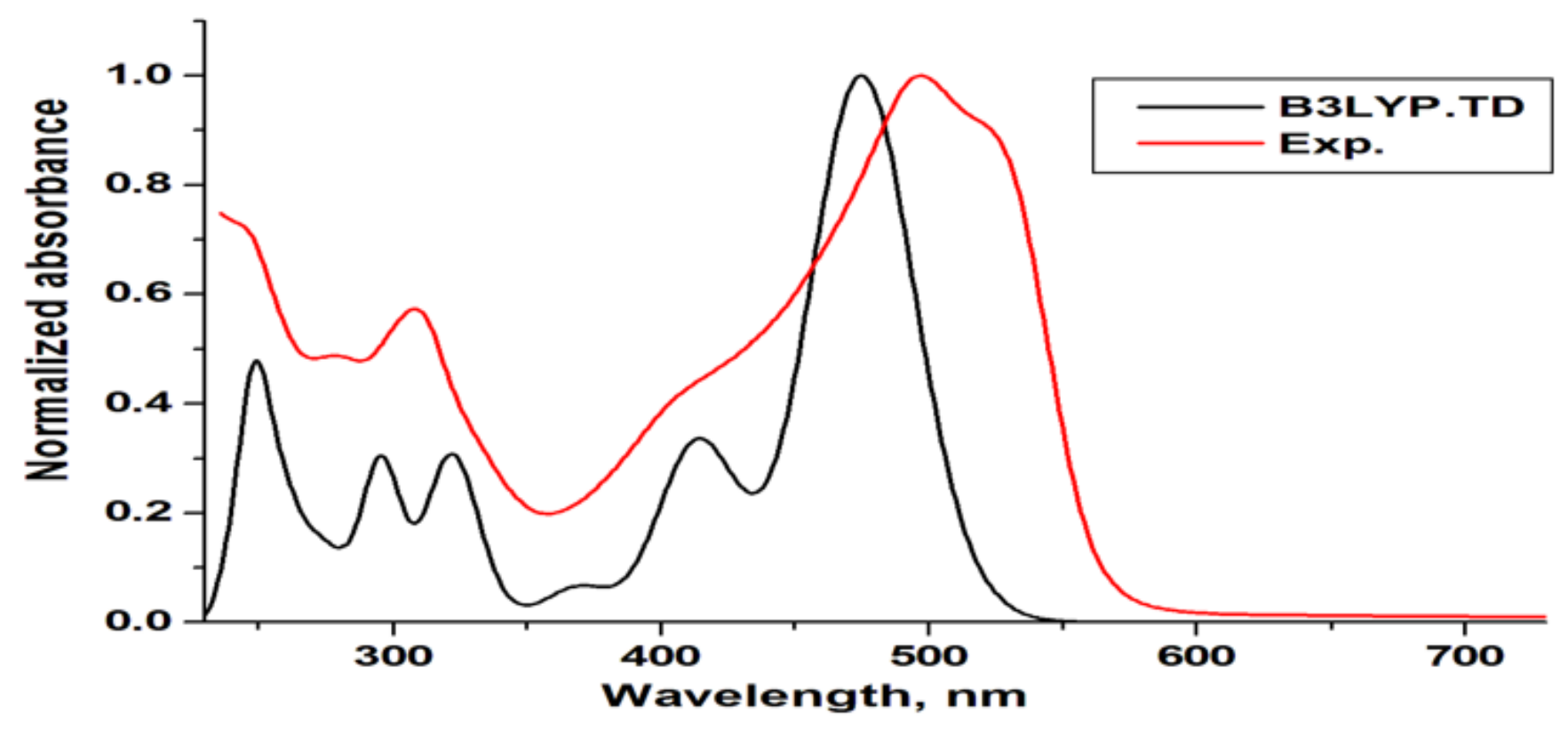

Figure 7

Experimental and theoretical UV/Visible spectra of dye (D1) obtained applying the TD-PCM-B3LYP (Water) /6-311++G(d,p) under level of approximation. 


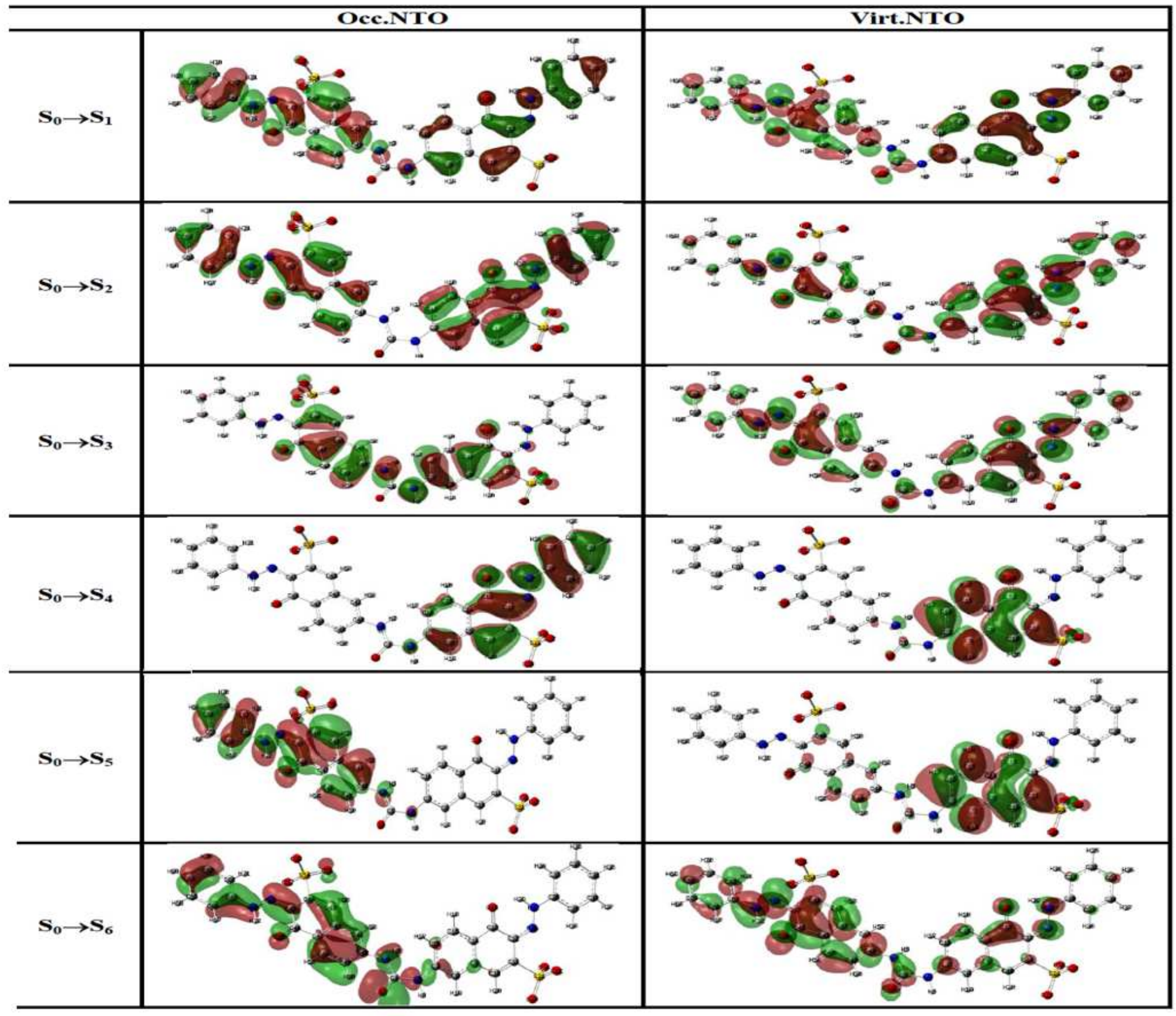

Figure 8

Natural transition orbitals (NTOs) occupied and non-occupied in the electronic transitions between the ground state (S0) and six low-lying singlet excited states (Sn) of D0-26 dye (D1) obtained at the PCMB3LYP (Water) /6-311++G(d,p) level of approximation.

\section{Supplementary Files}

This is a list of supplementary files associated with this preprint. Click to download.

- supportinginformation.docx

- Graphicalabstract.docx 